\title{
Site-specific partially nonergodic PSHA for a hard-rock critical site in southern France: adjustment of ground motion prediction equations and sensitivity analysis
}

\author{
Gabriele AMERI ${ }^{1 *}$, Fabrice HOLLENDER ${ }^{2}$, Vincent PERRON ${ }^{2}$, Christophe MARTIN $^{1}$
}

\author{
Affiliations: \\ ${ }^{1}$ Geoter SAS - Fugro, Auriol, France \\ ${ }^{2}$ CEA, Cadarache, Saint-Paul-lez-Durance, France \\ * Corresponding author, g.ameri@fugro.com, phone: +33 4 42360868, Fax: +33 442360861
}

\author{
Submitted to: \\ Bulletin of Earthquake Engineering \\ Date: 28/02/2017 (revised version)
}

\begin{abstract}
Modern probabilistic seismic hazard assessment (PSHA) focuses on the separation and different treatment of epistemic and aleatory uncertainties. Recent site-specific PSHA studies have pointed out that, if the site response and its epistemic uncertainties can be appropriately considered by adjustments to median estimates from ground motion prediction equations (GMPEs), the aleatory variability (sigma) of the GMPEs can be replaced by the single-station sigma thus partially relaxing the ergodic assumption employed in the PSHA. The site-specific partially nonergodic approach, correctly applied, provides a more accurate representation of the seismic hazard at a specific site and a more rigorous treatment of uncertainties.
\end{abstract}

This paper presents the strategy followed to apply this relatively recent approach to a critical infrastructure in Southern France located on hard-rock site conditions (Vs30 $\approx 2000 \mathrm{~m} / \mathrm{s}$ ). The target site conditions are defined in terms of shear-wave velocity (Vs) profiles and high-frequency attenuation $\left(\kappa_{0}\right)$ based on the results of site investigations and on the exploitation of earthquake records at seismic stations in the target site area. The host-to-target Vs- $\kappa_{0}$ adjustment of median estimates for the selected GMPEs is performed by using the inverse random vibration theory approach (Al Atik et al., 2014) considering epistemic uncertainties in target Vs profile and $\kappa_{0}$. The single-station sigma model is developed based on Rodriguez-Marek et al. (2013) due to the lack of local data. The results of the site-specific partially nonergodic PSHA are discussed by means of a sensitivity analysis and are compared to the results from standard ergodic PSHA. We found that, for the considered site, the sitespecific approach provides a substantial reduction (up to 50\%) of the uniform hazard spectra at 10000year return period compared to the ergodic approach. 


\section{Introduction}

Probabilistic seismic hazard assessment (PSHA) is commonly applied worldwide for the design or reassessment of critical infrastructures. In modern PSHA, ground motion prediction equations (GMPEs) are used to assess the ground motion distribution (median value and standard deviation) expected at a particular site as a function of earthquake magnitude, source-to-site distance, and other parameters (e.g., style of faulting).

Traditionally, PSHA for specific sites has been performed adopting what is called the ergodic assumption (Anderson and Brune, 1999). The ergodic assumption essentially states that variability over space can be used as a substitute for variation over time. It is used in practice because the sigma values, calculated from regression analyses of recorded data to develop GMPEs, represent the aleatory variability over space (i.e., across many different sites and regions), and indeed they are used in PSHA to describe the aleatory variability of ground motion at a single site over time.

Only recent studies focused on the fact that when performing a PSHA at a specific site, there are components of the ground motion (e.g., the site response) that are knowable and repeatable and thus should be treated as epistemic uncertainties. As a consequence the aleatory variability in the GMPEs should be reduced. For example, multiple recordings from similar events at individual sites generally display lower variability than indicated by the sigma values of GMPEs, leading to the concept of single-station sigma (Aktinson, 2006; Rodriguez-Marek et al., 2011; Luzi et al. 2014). Adjusting the GMPEs median estimates to account for site-specific response (and its uncertainty) and adopting the single station sigma leads to a partially nonergodic PSHA (e.g., Rodriguez-Marek et al., 2014; Bommer et al, 2015; Faccioli et al., 2015). It is partially nonergodic because only the variability among stations characterized by the same site parameterization (e.g., $\mathrm{Vs}_{30}$ value) is removed from the ergodic sigma of the GMPEs. Similarly, partially nonergodic region-specific GMPEs have been recently proposed (Kotha et al., 2016; Kuehn and Scherbaum 2016; Lanzano et al., 2016), where regional effects are considered with respect to global median GMPEs estimates and the region-specific sigma is found to be lower than the ergodic one.

A fully nonergodic approach would also remove repeatable effects in the source-to-source and path-topath variabilities of a GMPE. It would account, for example, for the fact that the contribution to the hazard at a site may come from few source regions with a certain source-to-site paths. On the other hand, in the datasets used to derive GMPEs, ground motions from many different source-to-site configurations are used. In order to perform a fully nonergodic PSHA, the ideal solution would be to have recorded at the target site earthquakes spanning a large magnitude range over a variety of distance. In this way, the derived empirical ground motion model would be completely site-specific. This is still difficult to do in practice because, despite the large growth of strong-motion networks worldwide, it is rare to have such a large set of recordings at one site. However, the number of high- 
quality datasets available for dense networks of station is increasing and studies on single-site and single-path ground motion variability have been performed (Lin et al., 2011; Villani and Abrahamson 2015; Lanzano et al., 2017).

An additional motivation toward the application of a partially nonergodic site-specific PSHA is to avoid double counting uncertainties. For example, if a standard ergodic PSHA is performed for rock condition at a site and then site response analysis is implemented to calculate the hazard at the ground surface, attention should be paid to the fact that part of the site response uncertainty is already included in the sigma of the GMPE (Rodriguez-Marek et al., 2014; Faccioli et al., 2015; Barani and Spallarossa, 2016).

This study presents a site-specific PSHA for a critical infrastructure in southern France located on hard rock site conditions (Vs30 of about $2000 \mathrm{~m} / \mathrm{s}$ ). When the ground motion needs to be estimated for such target site conditions two issues are faced. First, the reliability of empirical GMPEs is questionable because they are not well constrained for such Vs30 where only few records are available. Second, rock and hard-rock sites can have quite variable attenuation of the high-frequency seismic wavefield that have a strong impact on the ground motions potentially observed at the site. In particular, hardrock sites tend to present records with spectral content having a slower decay of amplitude with increasing frequency compared to standard rock sites. One widely used approach to characterize the high-frequency attenuation effect is through the estimation of the kappa $(\kappa)$ parameter that is empirically measured from the slope of the high-frequency portion of the Fourier spectrum of earthquakes recordings (Hanks, 1982; Anderson and Hough, 1984; Ktenidou et al., 2014). However, GMPEs typically do not account for kappa explicitly in the functional forms.

In the recent years, a noticeable amount of work has been dedicated to the adjustment of GMPEs to hard-rock conditions (e.g., Campbell, 2003; Cotton et al., 2006; Van Houtte et al., 2011; Al Atik, et al. 2014; Bora et al., 2015). For such adjustment, the combined effect of Vs profile and $\kappa$ has to be taken into account and it has a strong impact especially on the high-frequency content of the predicted acceleration response spectrum (Biro and Renault, 2012, Edwards et al., 2016).

In this paper, the approach followed for the site-specific partially nonergodic PSHA or a hard-rock site is illustrated focusing on the ground motion characterization. The following sections discuss the estimation of host and target Vs profiles and $\kappa$ values, the methodology followed for the adjustment of the median estimates for a set of GMPEs, the single station sigma model and the hazard results in terms of comparison between partially nonergodic and ergodic uniform hazard spectra. Since the application of partially nonergodic approaches in relatively new in PSHA practice, this paper may serve as a useful reference for future studies of this kind.

\section{Target site conditions and available data}


The studied site is located in the Southern-East part of France, within the Alpine foreland area, a region characterized by a low seismic activity (Figure 1) (Cushing et al., 2008). The seismicity level increases moderately east to the site, toward the Southern French Alps and the Ligurian basin, where the largest earthquakes occurred historically. The outcropping geological formation is composed by thick limestone beds from late Berriasian to Valanginian age (lower Cretaceous).

The evaluation of the target Vs- $\kappa$ conditions is based on characteristics obtained at two seismological stations, named S01 and S02 about $2 \mathrm{~km}$ distant from each other, both located within the industrial site of interest, in limestone outcropping areas (Figure 1). Station S02 is considered as control point for PSHA calculations. On S01 site, the shear-wave velocity profile was estimated by various characterization methods, using invasive approaches (cross-hole, down-hole and PS-suspension logging) and non-invasive methods, based on the analysis of dispersion features of surface waves (active "Multichannel Analysis of Surface Wave": MASW and passive "Ambient Vibration Arrays"). Detailed results of these measurements can be found in Garofalo et al. (2016a) and (2016b). On site S02, MASW experiment was conducted to assess velocity in the shallower layers while close crosshole measurements provided velocity values beneath $20 \mathrm{~m}$. However, the low quality of the MASW results essentially provided the Vs of the shallowest layer only. The synthesis of these Vs measurements is provided Figure 2.

On both sites, the Vs30 values computed strictly from surface to $30 \mathrm{~m}$ are around $1800 \mathrm{~m} / \mathrm{s}$. However, large industrial facilities foundations are often based deeper since soft weathered layers are removed before the construction. So, if one computes Vs30 below $3 \mathrm{~m}$, the obtained values are around $2100 \mathrm{~m} / \mathrm{s}$ for S01 and $1900 \mathrm{~m} / \mathrm{s}$ for S02. Note that the Vs30 for S02 is calculated by linear interpolation of the Vs values between those provided by the MASW and those provided by the cross-hole measurements.

Figure 2 also shows the Vs profiles, having several Vs30 values, used later for the host-to-target adjustments (see section 4.2).

The $\kappa$ parameter estimation is based on exploitation of earthquake records at both seismological stations S01 and S02. S01 provided accelerometric records over a period of 15 years from a triggered system. S02 provided broadband velocimetric records over a period of 2.5 years from a continuous system. Due to a better signal-to-noise ratio and the continuous recording mode, S02 provided roughly as much usable records as S01, despite a shorter recording period. Since the rock conditions of both sites are very similar, we used for the present study both data sets simultaneously for $\kappa$ estimation. More information on data processing and on $\kappa$ estimation at each station can be found in the dedicated paper by Perron et al. (2017). 
log-linear space of the high-frequency part of the acceleration FAS of the horizontal component of the shear waves. It can be expressed, for one given record of one given earthquake as:

$$
\operatorname{FAS}(\mathrm{f})=\mathrm{A}_{0} \exp (-\pi \kappa \mathrm{f}), \quad \mathrm{f}_{1}<f<\mathrm{f}_{2}
$$

where $f_{1}$ and $f_{2}$ are the frequency limits where the decay is approximately linear on a figure where acceleration in plotted in log scale and frequency is plotted in linear scale.

It is generally assumed that $\kappa$ depends on epicentral distance $\left(\mathrm{R}_{e}\right)$ (Douglas et al., 2010; Ktenidou et al., 2013). The notion of $\kappa_{0}$ is defined as extrapolation of $\kappa$ values, measured on numerous earthquake records on a given site, to zero epicentral distance:

$$
\kappa\left(\mathrm{R}_{e}\right)=\kappa_{0}+\kappa_{R} \cdot \mathrm{R}_{e}
$$

where $\tilde{\kappa}\left(\mathrm{R}_{e}\right)$ is the distance-dependence of $\kappa$ (Anderson, 1991). There are several methods proposed to compute $\kappa_{0}$ (Ktenidou et al. 2014). In this paper, $\kappa_{0}$ estimations are based on the original Anderson and Hough (1984) approach based on the slope of the high-frequency FAS (named " $\kappa_{0} \_A s$ ", in the following we drop the suffix AS for simplicity).

Figure 3 shows the different individual $\kappa$ values estimated on the S01 and S02 database and summarizes two approaches to estimate $\kappa_{0}$ and its uncertainty. The first approach (in green on Figure 3) consists in computing $\kappa_{0}$ and associated standard deviation using earthquakes with epicentral distances lower that $50 \mathrm{~km}$, considering a constant $\kappa$ in this distance range. This approach is rather robust since it does not introduced bias due to slope estimation. This approach leads to $\kappa_{0}$ value of $0.032 \mathrm{~s}$, with lower and upper bounds of $0.024 \mathrm{~s}$ and $0.038 \mathrm{~s}$, respectively. The second approach (in blue on Figure 3) is based on the computation of linear regressions on the whole epicentral distance range, minimizing and maximizing the possible $\kappa_{R}$ slope. This approach leads to $\kappa_{0}$ value of $0.032 \mathrm{~s}$ with lower and upper bounds of $0.021 \mathrm{~s}$ and $0.041 \mathrm{~s}$, respectively. Thus, with both approaches, we obtain $0.032 \mathrm{~ms}$ as a best-estimate value. The larger uncertainty interval is obtained with the second approach. In this study, we use the three target $\kappa_{0}$ values from the second approach to build a logic tree for the host-to-target adjustment in order to account for epistemic uncertainties.

\section{Overview of selected GMPEs}

Southeastern France is characterized by a low-to-moderate seismic activity with a limited number of strong-motion recordings in the magnitudes of interest for hazard estimates for critical infrastructures. The largest events recorded by the French strong-motion network (RAP) in the Alps do not exceed Mw 5. This limits the development of local empirical GMPEs and consequently the set of models used in PSHA are typically derived from foreign data. Several GMPEs have been tested in the past against a 
set of small-magnitude French records (Beauval et al., 2012) although the tested models have now been superseded by more recent ones.

For this study, we selected a set of six GMPEs composed by recent models including GMPEs developed within the NGA-West 2 project (Boore et al., 2014; Campbell \& Bozorgnia, 2014), models developed for the Pan-European region (Ameri, 2014; Akkar et al., 2014; Bindi et al., 2014) and the Cauzzi et al. (2015) model, mostly based on Japanese data (though it includes some records from elsewhere). These models satisfy the selection criteria of Cotton et al. (2006) further refined by Bommer et al. (2010), except for the Ameri (2104) model that was not published in a peer-reviewed journal at the time of this study (a refinement of this model has been recently published by Ameri et al. 2017) and it is included in the set as it considers a significant number of records from French earthquakes. The set of GMPEs selected in this study and their main characteristics are reported in Table 1. Note, anyway, that the purpose of this study is not to propose a set of GMPEs that should be definitely used for seismic hazard assessment in the region of interest. Similarly, the weighting of these GMPEs in the logic tree framework is beyond the scope of this paper.

In terms of ground motion estimation for hard-rock sites, the Pan-European models have very few data for sites with Vs30 > $1200 \mathrm{~m} / \mathrm{s}$ which limits their use for such cases. The NGA-West 2 models include a larger number of hard-rock sites and their use is recommended by the developers up to Vs30 $=1500$ $\mathrm{m} / \mathrm{s}$ (Gregor et al., 2014). In any case, regardless the GMPE, the estimation of ground motions for the hard-rock site of interest would require the extrapolation of the models far beyond their validity domains.

\section{Vs- $\kappa$ adjustment of median GMPEs estimates}

The median values predicted by GMPEs for generic site conditions need to be adjusted to the reference condition at the target site, defined in terms of Vs and $\kappa$ (see Section 2). The host-to-target adjustment is made considering a logic tree that accounts for the crustal Vs profiles and the three target $\kappa_{0}$ values defined for the site.

\section{1 methodology}

The approach for the Vs- $\kappa$ adjustment is similar to that used in other recent PSHA projects (Rodriguez-Marek et al., 2014; Renault 2014; Edwards et al., 2016). The methodology has been proposed by Al Atik et al. (2014) and it is based on the use of the Random Vibration Theory (RVT, Cartwright and Longuet-Higgins, 1956; Boore, 2003) and on the Inverse RVT (Gasparini and Vanmarcke, 1976; Rathje et al., 2005) that allows one to calculate an acceleration Fourier amplitude spectrum (FAS) compatible with a defined acceleration response spectra (for example from a GMPE), 
provided that a duration model is available. The main steps of the method are briefly outlined here and we refer to Al Atik et al. (2014) and Van Houtte et al. (2014) for further details.

The methodology considers the following steps:

1. for a specific scenario $(\mathrm{Mw}$, distance, fault mechanism,...) the host response spectrum is calculated for each GMPE for a standard rock condition;

2. the IRVT is applied in order to calculate the FAS compatible with the response spectrum defined in step 1. The empirical ground motion duration model of Bommer et al. (2009) is used in this study;

3. the host kappa value is estimated from the slope of the high-frequency portion of the calculated FAS (by fitting the exponential $\kappa$ function eq.(1) to the FAS);

4. the kappa adjustment is applied by multiplying the FAS by $\exp \left(-\pi \mathrm{f}\left(\kappa_{\text {target }}-\kappa_{\text {host }}\right)\right)$. If $\kappa_{\text {target }}<\kappa_{\text {host }}$ an additional step is required here to modify the host FAS such that the high-frequency slope follows the theoretical kappa scaling (Al Atik et al., 2014). This step is required due to the slope of the IRVT-derived FAS that tend to flatten at high frequencies;

5. the Vs adjustment is applied by multiplying the kappa-adjusted FAS of step 4 by the ratio target-to-host of the crustal amplifications (see section 4.2). This provides the Vs-kappa adjusted FAS;

6. the adjusted response spectra (target) is obtained by applying the RVT to the FAS obtained in step 5;

7. Vs- $\kappa$ adjustment factors in the response spectra domain are obtained by dividing the target spectrum (step 6) by the host one (step 1);

8. Steps 1 to 7 are repeated for several magnitude-distance scenarios for each GMPE.

\section{3 к adjustment}

Three values of target $\kappa_{0}$ are considered in this study for the GMPEs adjustment. As discussed in Section 2 , the central value is $\kappa_{0}=0.032 \mathrm{~s}$, the lower bound is $\kappa_{0}=0.021 \mathrm{~s}$ and the upper bound is $\kappa_{0}$ $=0.041 \mathrm{~s}$.

In order to estimate the host $\kappa$, the IRVT-derived FAS are calculated for several scenarios considering the selected GMPEs. The considered scenarios are $\mathrm{Mw}=5.0,5.5,6.0,6.5$ and distances of 5, 10 and 20 $\mathrm{km}$. The considered magnitude and distances are representatives of the hazard controlling sources for the target site for a return period of 10000 years (of interest for critical structures). Moreover, the consideration of short source-to-site distances is necessary in order to avoid, as much as possible, the effect of the anelastic attenuation (Q) on the calculated FAS that would otherwise affect the highfrequency part of the FAS and bias the host kappa estimation (Al Atik et al., 2014). The fault 
mechanism is strike-slip, which corresponds to the dominant mechanism of the most contributing sources. Other relevant parameters for the GMPEs are reported in Table 1.

For each scenario the kappa exponential model (eq. 1) is fitted to the high-frequency part of the FAS between two frequencies $f_{1}$ and $f_{2}$ that need to be determined. The selection of these two frequencies is not trivial and is source of uncertainty. Therefore, the kappa adjustment may be more or less affected by this choice. The minimum frequency $f_{1}$ shall be higher than the frequency associated with the peak amplitude of the FAS. The maximum frequency $f_{2}$ should be selected in order to ensure that the decrease of FAS between $f_{1}$ and $f_{2}$ is approximately linear (in the case of a lin-log graphical representation). We selected $\mathrm{f}_{1}$ and $\mathrm{f}_{2}$ based on visual inspection of calculated FAS. For each GMPE, we decided to consider a fixed frequency band regardless of the magnitude-distance scenarios considered. The minimum frequency $f_{1}$ is $8 \mathrm{~Hz}$ for all models and the maximum frequency $\mathrm{f}_{2}$ is $25 \mathrm{~Hz}$ for the model Cauzzi et al. (2014), $18 \mathrm{~Hz}$ for the model of Boore et al. (2014) and $20 \mathrm{~Hz}$ for other selected models. In this way, the impact of the choice of the frequency band on the host kappa estimation, which is to some extent subjective, is limited.

The determination of host $\kappa$, named $\kappa_{0, \mathrm{IRVT}}$, is illustrated in Figure 4 for several magnitudes at a distance of $10 \mathrm{~km}$. The host $\kappa_{0, \mathrm{IRVT}}$ values determined for each GMPE for all the considered magnitude-distance scenarios are reported in Table 2. Also reported is the mean $\kappa_{0, I R V T}$ value for each GMPE with relative standard deviation. We observe that for the Cauzzi et al. (2015) and Campbell \& Bozorgnia 2014 models we obtain lower $\kappa_{0, \text { IRVT }}$ values (around $0.024 \mathrm{~s}$ ) while for the remaining models values close to $0.03 \mathrm{~s}$ are obtained. Moreover, the Cauzzi et al. (2015) GMPE shows the smaller variability of $\kappa_{0, \text { IRVT }}$ while the Boore et al. (2014) model presents the largest variability. For this latter GMPE the $\kappa_{0, \text { IRVT }}$ values of about $0.03 \mathrm{~s}$ are obtained for the smallest magnitudes whereas values of about $0.037 \mathrm{~s}$ are obtained for larger magnitudes. This is due to the change in the shape of the response spectra between magnitudes 5.5 and 6 (not shown here). The peak of the response spectra is at about $10 \mathrm{~Hz}$ for $\mathrm{Mw}=5$ and at about $6 \mathrm{~Hz}$ for $\mathrm{Mw}=6$ (both at $\mathrm{R}_{\mathrm{JB}}=10 \mathrm{~km}$ ). Such an important shift of the peak of the response spectra (which is translated into the IRVT-derived FAS) is not observed for other GMPEs and may be related to the use of a period-dependent hinge magnitude $\left(\mathrm{M}_{\mathrm{h}}\right)$ in the Boore et al. (2014) model.

The stability of the $\kappa_{0, \text { IRVT }}$ estimated for the Cauzzi et al. (2015) model may be related to the underlying dataset composed exclusively by high-quality digital records. This would imply a lower level of high-frequency noise in the derived FAS compared to the other GMPEs and consequently a more precise estimation of the $\kappa_{0, \text { IRVT }}$ values. This is shown in Figure 4 where the for the Cauzzi et al. (2015) model the decay of the FAS follows the linear trend up to higher frequencies than for the other models allowing us to fix $\mathrm{f}_{2}$ to $25 \mathrm{~Hz}$. Another explanation could be an actual smaller variability of $\kappa_{0}$ values for stations in the Cauzzi et al. (2015) dataset. Indeed most of the dataset is composed by 
Japanese records and we may hypothesize that the considered rock sites are characterized by similar $\kappa_{0}$ values.

Concerning the variability of $\kappa_{0, I R V T}$ with distance, it is found to be significant for some of the considered GMPEs (i.e., Bindi et al., 2014; Ameri, 2014; Campbell and Bozorgnia, 2014) as reported in Table 2. For these models increasing distances provide generally larger $\kappa_{0, I R V T}$ values

\subsection{Vs adjustment}

The Vs adjustment aims to modify the median prediction of the GMPEs, initially determined for a generic Vs30 value, for a target Vs profile at the specific site. Thus, a target Vs profile representative of the type of rock encountered at the site and a host Vs profile, representative of the generic site conditions associated with the host Vs30 value shall be defined.

The approach followed is based on the use of generic Vs crustal profiles representative of the host and target rock conditions (Cotton et al., 2006; Biro and Renault, 2012; Rodriguez-Marek et al., 2014; Edwards et al., 2016). It consists in using the rock (Vs30=620 m/s) and hard-rock (Vs30=2880 m/s) generic Vs profiles defined by Boore \& Joyner (1997) (hereafter BJ97) to determine a representative crustal profile for a specified Vs30. The crustal profile for a target Vs30 is obtained by interpolating the BJ97 profiles as described by Boore (2016). Two target Vs crustal profiles are defined for the site in order to account for variability as depicted by the Vs measurements at the two stations (see section 2). The first (profile 1) is obtained by the abovementioned interpolation for a Vs $30=2000 \mathrm{~m} / \mathrm{s}$, which is the average of the Vs30 values at stations S01 and S02. The second (profile 2) is obtained by adopting the Vs profile for station S01 down to $20 \mathrm{~m}$ and the BJ97 hard-rock profile for deeper Vs (Figure 2). Profile 2 has a Vs30=1950 m/s, thus consistent with Profile 1.

Concerning the host Vs profile, we defined two generic rock profiles representative of a Vs30 $=800$ $\mathrm{m} / \mathrm{s}$ and Vs30 $=1000 \mathrm{~m} / \mathrm{s}$, respectively. The generic profile with Vs30 $=800 \mathrm{~m} / \mathrm{s}$ is used as a host Vs profile to adjust all the GMPEs except the Ameri (2014) model. Indeed, for this model, the site function is based on EC8 site classes and not on Vs30 (Table 1). This difference is due to the fact that the recording stations included in the dataset by Ameri (2014) are not all characterized in terms of Vs30 and for a large number of them, only the EC8 site classes based on local geology were available. As a consequence, we need to determine an equivalent Vs30 for the EC8 class A predictions of the Ameri (2014) model. This is not easy because, beside the missing Vs30, a number of stations may be mis-classified. Based on the analysis of the dataset of Ameri (2014) and the proportion of class A sites for which the Vs30 is available we suggest that a Vs $30=1000 \mathrm{~m} / \mathrm{s}$ can reasonably be associated with preditions for class A for this model. The generic host Vs profiles are presented in Figure 2.

The linear site amplifications for the host and target crustal profiles are calculated using the squareroot-impedance method (Boore, 2013) which is based on the quarter-wavelength approximation 
(Joyner et al., 1981). The effect of the attenuation will be included later by the kappa function. The amplitude transfer functions for the considered host and target profiles are presented in Figure 5 (left panel).

314 It is interesting to note that the amplifications calculated from profile 1 and 2 are similar. For frequencies lower than $20 \mathrm{~Hz}$ profile 2 provides lower amplifications due to the higher average Vs from the surface to the quarter-wavelength depth (which is approximately $75 \mathrm{~m}$ for $20 \mathrm{~Hz}$ ) with respect to profile 1. At higher frequencies, profile 2 provides larger amplifications due to the low average Vs in the shallower part of the profile (quarter-wavelength depth for $40 \mathrm{~Hz}$ is about $20 \mathrm{~m}$ ).

As suggested by Al Atik et al. (2014), the Vs adjustment is applied to the $\kappa$-corrected FAS (defined in step 4 of Section 4.1). Then the response spectrum is calculated by RVT (step 6) and adjustment factors in the response spectra domain can be determined (step 7). For purpose of illustration, the hostto-target adjustment factors for Vs only are shown in Figure 5 (right panel) for the defined profiles. We note that the Vs adjustment factors obtained considering the two target profiles are very similar. The use of profile 1 is overall slightly more conservative implying a smaller reduction of median spectral amplitudes from GMPEs. In order to avoid excessive and unjustified complexity of the ground-motion logic tree used in the PSHA, profile 1 is retained for the Vs-K adjustment that will be discussed in the next sections.

\subsection{Vs-к adjustment factors for the selected GMPEs}

In order to illustrate the effect of the Vs-א adjustment, the response spectra by the Akkar et al. (2014) GMPE for a particular scenario are adjusted for the target profile 1 (Vs30=2000) $\mathrm{m} / \mathrm{s}$ and several target $\kappa_{0}$ values (Figure 6). As expected, the effect of the $\kappa$ adjustment is negligible at low frequencies $(\mathrm{f}<1 \mathrm{~Hz}$ ) where the differences with respect to the original spectrum are due to the Vs adjustment. On the other hand, at high frequencies the effect of the $\kappa$ adjustment changes significantly both the amplitudes and the shape of the original response spectrum. At these frequencies the obtained spectra are a combination of the Vs and $\kappa$ effects. For very low $\kappa_{0}$ values, the reduction implied by the Vs adjustment is counter-balanced by the amplification due to the $\kappa$ scaling and the resulting spectra are larger than the original ones. In case of target $\kappa_{0}$ larger than the host $\kappa_{0, \text { IRVT }}$ both the Vs and $\kappa$ adjustments reduce the spectral amplitudes with respect to the original ones.

As we pointed out in the previous sections the estimated host $\kappa_{0, I R V T}$ values may be different for the considered GMPEs and as a consequence the Vs- $\kappa$ adjustment factors will depend on the GMPE. Moreover, for some of the models a variability of the estimated host $\kappa_{0, I R V T}$ with magnitude is observed, which is translated into variability in the adjustment factors. As an example we show in Figure 7 the adjustment factors obtained for the Vs-א adjustment of the Cauzzi et al. (2015) and the

344 Boore et al. (2014) GMPEs considering a target $\kappa_{0}=0.032 \mathrm{~s}$. Because the host $\kappa_{0, \text { IRVT }}$ values estimated 345 for the Cauzzi et al. (2015) show negligible variations with magnitude and distance, the obtained 
adjustment factors are similar. On the other hand, the adjustment of Boore et al. (2014) model provides two sets of factors in the high-frequency range. For $\mathrm{Mw}=5.0$ and 5.5 for which a host $\kappa_{0, \mathrm{IRVT}}$ of about $0.03 \mathrm{~s}$ is estimated, the amplitude reduction with respect to the original model is larger than for $\mathrm{Mw}=6.0$ and 6.5 for which the host $\kappa_{0, \mathrm{IRVT}}$ is estimated around $0.037 \mathrm{~s}$.

It is worth mentioning that the variability on the $\kappa_{0, I R V T}$ obtained for the selected GMPEs is considered and propagated in the following hazard calculations. The ground motion predicted by each GMPE in the PSHA calculations is adjusted considering the variation of scaling factors as a function of earthquake magnitude, if applicable. In this way, the uncertainties in the $\kappa_{0, I R V T}$ estimation are to some extent considered in the hazard calculations.

We compared the host-to-target Vs- $\kappa$ adjustment factors obtained for each GMPE for the three target $\kappa_{0}$ values in Figure 8. The comparison is presented for a scenario with $\mathrm{Mw}=5.5$ and distance of $10 \mathrm{~km}$, which corresponds to a magnitude-distance couple that significantly contribute to the seismic hazard at 10000-year return period. We observe that:

- At long periods $(\mathrm{T}>1 \mathrm{~s})$ the adjustment is controlled by the Vs profile. For this reason, the adjustment factors are essentially the same for all GMPEs except for the Ameri (2014) model. As already mentioned, for this model the host Vs 30 is $1000 \mathrm{~m} / \mathrm{s}$ while a Vs $30=800 \mathrm{~m} / \mathrm{s}$ is used for the other GMPEs;

- In general, regardless of the target $\kappa_{0}$ value considered, the adjustment factors are smaller than 1 for all GMPEs. This means that the host-to-target adjustment reduces the ground motions for this particular hard-rock site. For example, for the central target $\kappa_{0}=0.032 \mathrm{~s}$ the reduction with respect to the host GMPEs is of about $20 \%$ at long periods and of $40 \%$ to $60 \%$ at short periods;

- The adjustment factors are overall consistent among the GMPEs. This is due to the similar host $\kappa_{0, I R V T}$ values and Vs adjustment. Exceptions are the the Cauzzi et al. (2015) and Campbell \& Bozorgnia (2014) models that are characterized by smaller $\kappa_{0, I R V T}$ values and thus leads to smaller adjustment factors (i.e., larger reductions with respect to generic host conditions).

\section{Single-station sigma model}

In the framework of the site-specific partially nonergodic approach, the part of the ground motion aleatory variability of the GMPEs which corresponds to the inter-site variability should be removed. Indeed, the median prediction of the GMPEs is adjusted for site-specific Vs profile and $\kappa_{0}$ considering epistemic uncertainties, then the sigma should be reduced by an amount reflecting site-term variability in order to avoid double counting. 
The single-station sigma $\left(\sigma_{\mathrm{ss}}\right)$, and more precisely the event-corrected single-station standard deviation $\left(\phi_{\mathrm{ss}}\right)$, can be estimated empirically provided that sufficient records are available on the site (e.g., Rodriguez-Marek et al, 2011; Chen and Faccioli, 2013; Luzi et al, 2014). Nevertheless, in the case of a limited number of records, as for the present study, the $\sigma_{\mathrm{ss}}$ model developed by Rodriguez-Marek et al. (2013) can be considered. The authors compiled a ground motion database from several tectonically active regions in order to establish a global estimate for this parameter. The results show that the value of $\phi_{\mathrm{ss}}$, is remarkably stable in all the considered regions. They proposed different models for $\phi_{\mathrm{ss}}$ : a homoscedastic model (only function of the spectral period), and heteroscedastic models (depending on the magnitude and / or distance). In this study, the homoscedastic model is considered..

The epistemic uncertainties on $\phi_{\mathrm{ss}}$ need also to be considered to account for the variability of $\phi_{\mathrm{ss}}$ at each single site $\left(\phi_{\mathrm{ss}, \mathrm{s}}\right)$. Following, Rodriguez-Marek et al. (2014) a coefficient of variation of 0.1 (i.e., std $\left.\phi_{\mathrm{ss}}=0.1 * \phi_{\mathrm{ss}}\right)$ is used based on the variability of $\phi_{\mathrm{ss}}$ estimated from the PEGASOS Refinement Project global dataset of $\phi_{\mathrm{ss}, \mathrm{s}}$ (swissnuclear, 2014). In the PSHA calculations, the epistemic uncertainty of $\phi_{\mathrm{ss}}$ was assumed to be normally distributed and was modeled using a three-point distribution that maintains the mean and standard deviation of the original distribution. The high $\phi_{\mathrm{ss}}$ was taken as the median $\phi_{\mathrm{ss}}+1.6 \operatorname{std}\left(\phi_{\mathrm{ss}}\right)$, and the low $\phi_{\mathrm{ss}}$ was taken as the median $\phi_{\mathrm{ss}}-1.6 \operatorname{std}\left(\phi_{\mathrm{ss}}\right)$.

The single station sigma $\left(\sigma_{\mathrm{ss}}\right)$ logic tree is finally defined by the following three branches and weights:

$$
\sigma_{s s}=\sqrt{\phi_{s s}^{2}+\tau^{2}}, \text { weight }=0.6
$$

$$
\sigma_{\text {ss }, \text { upper }}=\sqrt{\left(\phi_{s s}+1.6 * s t d \phi_{s s}\right)^{2}+\tau^{2}}, \text { weight }=0.2
$$

$$
\sigma_{s s, \text { lower }}=\sqrt{\left(\phi_{s s}-1.6 * s t d \phi_{s s}\right)^{2}+\tau^{2}}, \text { weight }=0.2
$$

Several approaches can be followed to define the between-event variability $(\tau)$. One approach is to consider the model of $\tau$ as defined in each GMPE, which leads to a $\sigma_{\mathrm{ss}}$ model for each GMPE. Alternatively, a single $\tau$ model can be considered, meaning that this is the preferred between-event variability in the study area. In this latter approach, a single $\sigma_{\mathrm{ss}}$ model is defined and used for all GMPEs (Rodriguez-Marek et al, 2014). For this study, the second approach is adopted. The $\tau$ value considered is that of the Ameri (2014) GMPE because, among the selected models, it is the only one that consider in the dataset a large number the events located in the study region (i.e., French Alps). Figure 9 shows the total and the between-event $(\tau)$ standard deviations of the selected GMPEs, the median $\phi_{\text {ss }}$ proposed by Rodriguez-Marek et al. (2013), and the $\sigma_{\mathrm{ss}}$ model (median, lower and upper) considered in this study. Note that the $\tau$ for the Ameri (2014) model is larger compared to most of the other GMPEs, and in particular to other Pan-European models (Bindi et al., 2014 and Akkar et al., 2014). This is at least partially due to the consideration of small magnitude events from France and 
Switzerland that increase the between-event variability at short periods. According to Ameri (2014) part of such variability can be ascribed to variability in stress parameter for such small magnitude events (e.g., Drouet et al., 2010). Note that, the considered $\sigma_{\mathrm{ss}}$ values are comparable to the total sigma values defined by Boore et al. (2014) and Campbell and Bozorgnia (2014).

\section{Sensitivity of hazard results to the GMPEs adjustment}

In order to illustrate the impact of the GMPEs adjustment and the use of the single-station sigma on the hazard estimation at the site, we compare uniform hazard spectra obtained by the site-specific partially nonergodic and generic ergodic PSHA. For the purpose of this paper a simplified SSC model is considered because we are interested in showing the hazard sensitivity to the GMPEs adjustment. The simplified SSC model consists of one of the area source models (named SM1) considered in the global logic tree which accounts for seismic source up to $200 \mathrm{~km}$ from the target site (Figure 1) for which best-estimates seismicity parameters are used. The minimum magnitude considered in the PSHA calculations is $\mathrm{Mw}=5$, which is a value typically considered for critical structures.

The hazard calculations are performed with the Crisis 2014 V1.2 software (Ordaz et al., 2013). We considered 15 spectral periods ranging between $0.01 \mathrm{~s}$ to $3 \mathrm{~s}$, which encompass the typical periods of interest for the several parts of the structure.

The aim of this sensitivity analysis is to show: 1) the impact, for each GMPE, of the application of the site-specific partially nonergodic PSHA with respect to the standard ergodic PSHA; 2) the impact of the three target $\kappa_{0}$ values (central, upper and lower bounds) in the site-specific PSHA and 3) the overall impact of the application of the site-specific partially nonergodic approach with respect to the standard generic approach when using the selected GMPEs in the logic tree. The hazard sensitivity is presented in terms of UHS at 10000-year return period.

The hazard results are shown on Figure 10, where for each GMPE the UHS for standard rock conditions using the ergodic approach are compared to those obtained from the site-specific partially nonergodic approach for the three target $\kappa_{0}$ values. Thus the UHS for the three target $\kappa_{0}$ values represent the epistemic uncertainties related to the target hard-rock site response. The ergodic UHS are calculated considering both a Vs30=800 m/s and a Vs30 which represents the upper limit of the validity domain as recommended for each GMPE (Table 1).

Generally speaking, the UHS obtained by the partially nonergodic PSHA are lower than the ergodic ones. This is due to the combined effect of the Vs- $\kappa$ adjustment and of the single-station sigma model. It is interesting to note that the Boore et al. (2014) and the Campbell and Bozorgnia (2014) models provide ergodic UHS for $\mathrm{Vs} 30=1500 \mathrm{~m} / \mathrm{s}$ which are similar to the partially nonergodic UHS at low frequencies. Note that for these two GMPEs the differences between the generic and site-specific UHS 
can be exclusively ascribed to the Vs- $\kappa$ adjustment of median estimations because the adopted singlestation sigma values are very similar to the ergodic sigma that comes with these models.

The site-specific partially nonergodic mean UHS from the simplified SSC logic tree is presented in Figure 11 adopting equal weights for the GMPEs and for the three target $\kappa_{0}$ values. We also show the generic ergodic UHS obtained considering Vs30=800 m/s and Vs30 equal to the upper limit of the validity domain prescribed by each GMPE. The site-specific UHS provides PGA value about $50 \%$ lower than the generic one. At $1 \mathrm{~Hz}$, the site-specific UHS is about $40 \%$ lower than the generic one for Vs $30=800 \mathrm{~m} / \mathrm{s}$ and $20 \%$ lower than the one for upper limit Vs30.

\section{Summary and Conclusions}

When conducting a site-specific PSHA, epistemic and aleatory uncertainties should be clearly identified and treated separately. The consideration of the site-specific characteristics of the target site, and associated uncertainties, allows us to partially remove the ergodic assumption in the aleatory variability of the GMPEs by considering that the site response is known and thus can be modelled as alternative branches of the logic tree (epistemic uncertainties). This is a clear advance in the PSHA practice because it allows a more rigorous treatment of uncertainties and a more accurate representation of the ground motion at a specific site.

A site-specific partially nonergodic PSHA is performed for a hard-rock site in Southern France, a region of low-to-moderate seismicity. The results presented in this paper focused on the ground motion characterization in terms of host-to-target adjustment of median estimates from GMPEs and of the definition of the single-station sigma model.

The target reference site conditions are defined in terms of Vs profiles and $\kappa_{0}$ values based on the results of site investigations and on the exploitation of earthquake records at seismic stations in the target site area. Two alternative target Vs profiles were considered in order to consider epistemic uncertainties, both having a Vs30 of about $2000 \mathrm{~m} / \mathrm{s}$. Only one target profile was finally retained because the two profiles provided similar Vs adjustments factors. In order to considered uncertainties in the target $\kappa_{0}$, three branches were considered in the adjustment of the GMPEs (i.e., $\kappa_{0}=0.032 \mathrm{~s}$, $\kappa_{0}=0.021 \mathrm{~s}$ and $\kappa_{0}=0.041 \mathrm{~s}$ ) based on measured $\kappa$ values on acceleration records in the site area.

The estimation of the host $\kappa_{0}$ is performed via IRVT on FAS compatible with the response spectra of the selected GMPEs for several magnitude-distance scenarios. The $\kappa_{0, I R V T}$ values are found to be similar among the GMPEs with values of about $0.03 \mathrm{~s}$ for 4 out of 6 models and $\kappa_{0, \text { IRVT }}$ of about $0.025 \mathrm{~s}$ for the remaining two models. However, the variability of $\kappa_{0, I R V T}$ for each GMPE can be relevant depending on the GMPE. This variability was considered and propagated in PSHA calculations by using, for the GMPEs that show this variability, a set of adjustment factors for each target $\kappa_{0}$.

Finally, the ergodic assumption was partially removed by adjusting the median GMPEs estimates for the target Vs- $\kappa$ conditions, including uncertainties, and by reducing the aleatory variability of the 
GMPEs using a single-station sigma model which included epistemic uncertainties in the eventcorrected single-station sigma $\left(\phi_{\mathrm{ss}}\right)$.

The impact of the site-specific partially nonergodic approach on PSHA results was presented by means of a sensitivity analysis showing the UHS at 10000-year return period for different branches of the ground motion logic tree. The site-specific UHS were compared to generic ones calculated considering standard rock conditions (Vs30=800 m/s) and hard-rock conditions by using the upper Vs30 limit for the selected GMPEs. For the considered site, the site-specific approach provided a substantial reduction of the UHS at 10000-year return period compared to the ergodic approach. The reduction is larger at high frequencies. This is due to the fact that for this specific site, both the Vs and $\kappa$ adjustments reduces the ground motion amplitudes with respect to the host conditions. The reduction of the ergodic sigma also contributes to the lower acceleration values obtained by the site-specific approach.

The approach presented in this study provides a more accurate definition of the seismic hazard at the site of interest and it is definitely worth pursuing when data at the site (or in the site proximity) are available for the target $\kappa_{0}$ estimation. In this sense, this study also demonstrates the usefulness of having seismic instrumentation at critical sites which allows gathering and exploiting earthquake recordings to characterize the site conditions.

\section{Acknowledgments}

This study was supported by the "Commissariat à l'énergie atomique et aux énergies alternatives" (CEA) and by the SeIsmic Ground-Motion Assessment (SIGMA) Project (funded by EDF, AREVA, CEA and ENEL). Discussion with SIGMA project scientific committee and participants is greatly acknowledged. We thank two anonymous reviewers whose comments led to improvementsto the manuscript.

\section{References}

Al Atik, L., Kottke, A., Abrahamson, N., and J. Hollenback (2014) Kappa (к) Scaling of GroundMotion Prediction Equations Using an Inverse Random Vibration Theory Approach, Bull. Seismol. Soc. Am. 104:336-346.

Akkar S., Sandikkaya M.A. and J.J. Bommer (2014). Empirical Ground-Motion Models for Point- and Extended-Source Crustal Earthquake Scenarios in Europe and the Middle East. Bulletin of Earthquake Engineering, February 2014, Volume 12, Issue 1, pp 359-387.

Ameri G. (2014). Empirical Ground Motion Model adapted to the French context. Deliverable SIGMA: SIGMA-2014-D2-131.

Anderson, J. (1991). A preliminary descriptive model for the distance-dependence of the spectral decay parameter in southern California. Bulletin of the Seismological Society of America 81 (6), 2186-2193

Anderson, J. G., and S. E. Hough (1984). A model for the shape of the fourier amplitude spectrum of acceleration at high frequencies, Bull. Seismol. Soc. Am. 74, 1969-1993. 
Anderson, J. G., and J. N. Brune (1999). Probabilistic seismic hazard assessment without the ergodic assumption, Seismol. Res. Lett. 70, 19-28.

Atkinson, G. (2006). Single-station sigma, Bull. Seism. Soc. Am. 96, 446-455.

Barani S. and D. Spallarossa (2016) - Soil amplification in probabilistic ground motion hazard analysis, Bulletin of Earthquake Engineering, DOI 10.1007/s10518-016-9971-y

Bindi D., Massa M., Luzi L., Ameri G., Pacor F.,Puglia R. and P. Augliera (2014) Pan-European Ground-Motion Prediction Equations for the Average Horizontal Component of PGA, PGV, and 5\%-Damped PSA at Spectral Periods up to $3.0 \mathrm{~s}$ using the RESORCE dataset. Bulletin of Earthquake Engineering, 12, 1, p. 391-430.

Bommer, J. J., P. J. Stafford, and J. E. Alarcón (2009). Empirical equations for the prediction of the significant, bracketed, and uniform duration of earthquake ground motion, Bull. Seismol. Soc. Am. $99,3217-3233$

Bommer, J.J., K. J. Coppersmith, R. T. Coppersmith, K. L. Hanson, A. Mangongolo, J. Neveling, E.M. Rathje, A. Rodriguez-Marek, F. Scherbaum, R. Shelembe, P. J. Stafford, and F. O. Strasser (2015) A SSHAC Level 3 Probabilistic Seismic Hazard Analysis for a New-Build Nuclear Site in South Africa. Earthquake Spectra: May 2015, Vol. 31, No. 2, pp. 661-698.

Bora, S. S., Scherbaum, F., Kuehn, N., P. Stafford and B. Edwards. (2015). Development of a Response Spectral Ground-Motion Prediction Equation (GMPE) for Seismic-Hazard Analysis from Empirical Fourier Spectral and Duration Models, Bulletin of the Seismological Society of America, 105, 4, p. 2192-2218.

Boore, D. M. and W. B. Joyner (1997). Site amplifications for generic rock sites, Bull.Seismol.Soc.Am.,87, 327-341.

Boore, D. M. (2003). Simulation of ground motion using the stochastic method, Pure and Applied Geophysics 160, 635-675

Boore, D. M. (2013). The uses and limitations of the square-root impedance method for computing site amplification, Bull. Seismol. Soc. Am. 103, 2356--2368

Boore, D.M., Stewart J.P., Seyhan E., and G.M. Atkinson (2014). NGA-West 2 equations for predicting PGA, PGV, and 5\%-damped PSA for shallow crustal earthquakes, Earthquake Spectra, 30, p. 1057-1085.

Boore, D.M. (2016). Determining Generic Velocity and Density Models for Crustal Amplification Calculations, with an Update of the Boore and Joyner (1997) Generic Site Amplification for $V_{S}(Z)=760 \mathrm{~m} / \mathrm{s}$, Bull. Seismol. Soc. Am. 106, 316--320.

Campbell K. W. and Y. Bozorgnia. (2014). NGA-West2 Ground Motion Model for the Average Horizontal Components of PGA, PGV, and 5\%-Damped Linear Acceleration Response Spectra. Earthquake Spectra, Volume 30, No. 3, pages 1087-1115.

Cartwright, D., and M. Longuet-Higgins (1956). The statistical distribution of the maxima of a random function, Proc. Roy. Soc. Lond. Math. Phys. Sci. 237, no. 1209, 212-232.

Cauzzi C., Faccioli E., Vanini M. and A. Bianchini (2015). Updated predictive equations for broadband (0.01 to $10 \mathrm{~s})$ horizontal response spectra and peak ground motions, based on a global dataset of digital acceleration records. Bulletin of Earthquake Engineering, 13, 6, p. $1587-1612$

Chen, L. and E. Faccioli (2013). Single-station standard deviation analysis of 2010-2012 strongmotion data from the Canterbury region, New Zealand, Bull. Earthq. Eng. 11, 1617-1632.

Cotton, F., F. Scherbaum, J. J. Bommer, and H. Bungum (2006). Criteria for selecting and adjusting ground-motion models for specific target regions: Application to central Europe and rock sites, J. of Seismology, 10, 137-156. DOI: 10.1007/s10950-005-9006-7. 
Cushing, E. M., Bellier, O., Nechtschein, S., Sébrier, M., Lomax, A., Volant, Ph., Dervin, P., Guignard, P. and Bove, L. (2008), A multidisciplinary study of a slow-slipping fault for seismic hazard assessment: the example of the Middle Durance Fault (SE France). Geophysical Journal International, 172: 1163-1178. doi:10.1111/j.1365-246X.2007.03683.x

Douglas, J., Gehl, P., Bonilla, L.F., Gélis, C. (2010). A к Model for Mainland France. Pure Appl. Geophys. 167, 1303-1315. doi:10.1007/s00024-010-0146-5

Drouet, S., F. Cotton, and P. Guéguen (2010). VS30, $\kappa$, regional attenuation and Mw from small magnitude events accelerograms, Geophys. J. Int. 182, 880-898.

Edwards B., Cauzzi C., Danciu L., and D. Fäh (2016) Region-specific Assessment, Adjustment and Weighting of Ground Motion Prediction Models: application to the 2015 Swiss Seismic Hazard Maps. Accepted for publication in the Bulletin of the Seismological Society of America

Faccioli, E., Paolucci, R., and M. Vanini (2015) Evaluation of Probabilistic Site-Specific SeismicHazard Methods and Associated Uncertainties, with Applications in the Po Plain, Northern Italy Bulletin of the Seismological Society of America , 105, 2787-2807

Garofalo F., S. Foti, F. Hollender, P.Y. Bard, C. Cornou, B.R. Cox, M. Ohrnberger, D. Sicilia, M. Asten, G. Di Giulio, T. Forbriger, B. Guillier, K. Hayashi, A. Martin, S. Matsushima, D. Mercerat, V. Poggi, H. Yamanaka (2016a). InterPACIFIC project: Comparison of invasive and non-invasive methods for seismic site characterization. Part I: Intra-comparison of surface wave methods, Soil Dynamics and Earthquake Engineering, 82, 222-240.

Garofalo F., S. Foti, F. Hollender, P.Y. Bard, C. Cornou, B.R. Cox, A. Dechamp, M. Ohrnberger, V. Perron, D. Sicilia, D. Teague, C. Vergniault (2016b). InterPACIFIC project: Comparison of invasive and non-invasive methods for seismic site characterization. Part II: Inter-comparison between surface-wave and borehole methods, Soil Dynamics and Earthquake Engineering, 82, 241-254.

Gasparini, D. A., and E. H. Vanmarcke (1976). SIMQKE: Simulated earthquake motions compatible with prescribed response spectra, Department of Civil Engineering, Research Report R76-4, Massachusetts Institute of Technology, Cambridge, Massachusetts.

Gregor, N., N. A. Abrahamson, G. M. Atkinson, D. M. Boore, Y. Bozorgnia, K. W. Campbell, B. S. J. Chiou, I. M. Idriss, R. Kamai, E. Seyhan, W. Silva, J. P. Stewart and R. Youngs (2014). Comparison of Nga-West2 GMPEs, Earthq Spectra 30, 1179-1197

Joyner,W. B., R. E.Warrick, and T. E. Fumal (1981). The effect of Quaternary alluvium on strong ground motion in the Coyote Lake, California, earthquake of 1979, Bull. Seismol. Soc. Am. 71, 1333-1349.

Kotha, S. R., Bindi, D., Cotton, F. (2016). Partially nonergodic region specific GMPE for Europe and Middle-East. - Bulletin of Earthquake Engineering, 14, 4, 1245-1263.

Ktenidou, O.-J., F. Cotton, N. Abrahamson, and J. Anderson (2014). Taxonomy of kappa: A review of definitions and estimation approaches targeted to applications, Seismol. Res. Lett. 85, no. 1, doi:10.1785/0220130027.

Ktenidou, O.-J., C. Gélis, and L.-F. Bonilla (2013). A study on the variability of kappa (к) in a borehole: Implications of the computation process, Bull. Seismol. Soc. Am. 103, no. 2A, 10481068 .

Kuehn N.M and Scherbaum F. (2016), A partially nonergodic ground-motion prediction equation for Europe and the Middle East, Bulletin of Earthquake Engineering, doi:10.1007/s10518-016-9911$\mathrm{x}$ 
Lanzano G., M. D’Amico, C. Felicetta, R. Puglia, L. Luzi, F. Pacor, and D. Bindi (2016) GroundMotion Prediction Equations for Region-Specific Probabilistic Seismic-Hazard Analysis, Bull. Seismol. Soc. Am. 106, 73-92

Lanzano G., F. Pacor, L. Luzi, M. D’Amico, R. Puglia and C. Felicetta (2017) Empirical regionspecific ground motion variability: the case study of Northern Italy, submitted to Bulletin of Earthquake Engineering

Lin, P.-S., B. Chiou, N. Abrahamson, M. Walling, C.-T. Lee, and C.-T. Cheng (2011). Repeatable source, site, and path effects on the standard deviation for empirical ground-motion prediction models, Bull. Seismol. Soc. Am. 101, no. 5, 2281-2295.

Luzi L., D. Bindi, R. Puglia, F. Pacor, and A. Oth (2014). Single-Station Sigma for Italian StrongMotion Stations, Bull. Seismol. Soc. Am., Vol. 104, No. 1, pp. 467-483.

Ordaz, M., F. Martinelli, V. D'Amico, and C. Meletti (2013). Crisis2008: A flexible tool to perform probabilistic seismic hazard assessment, Seismol. Res. Lett. 84, 495-504.

Perron, V., F. Hollender, P.-Y. Bard, C. Gélis, C. Guyonnet-Benaize, B. Hernandez and O.-J. Ktenidou (2017). Site-specific estimation of kappa in the low-to-moderate seismicity context of Provence, France. Submitted to Bulletin of the Seismological Society of America.

Rathje, E. M., A. R. Kottke, and M. C. Ozbey (2005). Using inverse random vibration theory to develop input Fourier amplitude spectra for use in site response, in 16th International Conference on Soil Mechanics and Geotechnical Engineering: TC4 Earthquake Geotechnical Engineering Satellite Conference, Osaka, Japan, 12-16 September, 160-166.

Renault P. (2014). Approach and challenges for the seismic hazard assessment of nuclear power plants: the Swiss experience. Bollettino di Geofisica Teorica ed Applicata, Vol. 55, n. 1, pp. 149164.

Rodriguez-Marek, A., G. A. Montalva, F. Cotton, and F. Bonilla (2011). Analysis of single-station standard deviation using the KiK-net data, Bull. Seismol. Soc. Am. 101, 1242-1258.

Rodriguez-Marek A., F. Cotton, N. A. Abrahamson, S. Akkar, L. Al Atik, B. Edwards, G. A. Montalva, and H. M. Dawood (2013) A Model for Single-Station Standard Deviation Using Data from Various Tectonic Regions, Bull. Seismol. Soc. Am., Vol. 103, No. 6,doi: $10.1785 / 0120130030$

Rodriguez-Marek, A., Rathje, E.M., Stafford, P.J., Scherbaum, F., and Bommer, J.J., (2014). Application of single-station sigma and site response analyses in a probabilistic seismic hazard analysis for a new nuclear site, Bull. Seismol. Soc. Am., 104:1601-1619.

Swissnuclear, 2014 [Renault P., Abrahamson, N, et al.]. "PEGASOS Refinement Project: Volume 4 SP2 - Ground Motion Characterization". Available at http://www.swissnuclear.ch/en/downloads_content---1--1058.html

Villani M. and N.N Abrahamson (2015) Repeatable Site and Path Effects on the Ground-Motion Sigma Based on Empirical Data from Southern California and Simulated Waveforms from the CyberShake Platform, Bull. Seismol. Soc. Am., 105,2681-2695

Van Houtte, C., S. Drouet, and F. Cotton (2011). Analysis of the origins of $\kappa$ (kappa) to compute hard rock to rock adjustment factors for GMPEs, Bull. Seismol. Soc. Am. 101, no. 6, 2926-2941

Van Houtte C., Ktenidou O.-J.., Larkin T. and C. Holden (2014) Hard-Site $\kappa_{0}$ (Kappa) Calculations for Christchurch, New Zealand, and Comparison with Local Ground-Motion Prediction Models, Bull. Seismol. Soc. Am., 104, 1899-1913 


\begin{tabular}{|c|c|c|c|c|c|c|}
\hline & region & Mw range & Distance range & $\begin{array}{l}\text { Period } \\
\text { range }\end{array}$ & Site & $\begin{array}{l}\text { Vs30 } \\
\text { range }\end{array}$ \\
\hline Ameri (2014)* & $\begin{array}{c}\text { Europe } \\
\text { and Middle } \\
\text { East }\end{array}$ & $3.0-7.6$ & $\begin{array}{c}\mathrm{R}_{\mathrm{JB}, \mathrm{EPI}}=0-200 \\
\mathrm{~km}\end{array}$ & $0-3 \mathrm{sec}$ & $\begin{array}{c}\text { EC8 } \\
\text { classes }\end{array}$ & - \\
\hline $\begin{array}{c}\text { Akkar et al. } \\
\quad(2014)\end{array}$ & $\begin{array}{c}\text { Europe } \\
\text { and Middle } \\
\text { East }\end{array}$ & $4.0-7.6$ & $\begin{array}{c}\mathrm{R}_{\mathrm{JB}, \mathrm{EPI}, \mathrm{HYP}}=0- \\
200 \mathrm{~km}\end{array}$ & $0-4 \mathrm{sec}$ & $\mathrm{V}_{\mathrm{s} 30}$ & $\begin{array}{c}150-1200 \\
\mathrm{~m} / \mathrm{s}\end{array}$ \\
\hline $\begin{array}{l}\text { Bindi et al. } \\
\quad(2014)\end{array}$ & $\begin{array}{c}\text { Europe } \\
\text { and Middle } \\
\text { East }\end{array}$ & $4.0-7.6$ & $\begin{array}{c}\mathrm{R}_{\mathrm{JB}, \mathrm{HYP}}=0-300 \\
\mathrm{~km}\end{array}$ & $0-3 \mathrm{sec}$ & $\mathrm{V}_{\mathrm{s} 30}$ & $\begin{array}{c}150-1200 \\
\mathrm{~m} / \mathrm{s}\end{array}$ \\
\hline $\begin{array}{c}\text { Boore et al. } \\
(2014)^{\star \star}\end{array}$ & Global & $3.5-8.5$ & $\mathrm{R}_{\mathrm{JB}}=0-400 \mathrm{~km}$ & $\begin{array}{c}0-10 \\
\text { sec }\end{array}$ & $\mathrm{V}_{\mathrm{s} 30}$ & $\begin{array}{c}150-1500 \\
\mathrm{~m} / \mathrm{s}\end{array}$ \\
\hline $\begin{array}{c}\text { Cauzzi et al. } \\
(2015)\end{array}$ & $\begin{array}{l}\text { Global (mostly } \\
\text { japan) }\end{array}$ & $4.5-7.9$ & $\mathrm{R}_{\mathrm{RUP}}=0-150 \mathrm{~km}$ & $0-10 \mathrm{sec}$ & $\mathrm{V}_{\mathrm{s} 30}$ & $\begin{array}{c}150-1200 \\
\mathrm{~m} / \mathrm{s}\end{array}$ \\
\hline $\begin{array}{c}\text { Campbell \& } \\
\text { Bozorgnia } \\
(2014)++\end{array}$ & Global & 3.3-8.5 & RRUP $=0-300 \mathrm{~km}$ & $0-10 \mathrm{sec}$ & $\mathrm{V}_{\mathrm{s} 30}$ & $\begin{array}{c}150-1500 \\
\mathrm{~m} / \mathrm{s}\end{array}$ \\
\hline
\end{tabular}

Table 1: Main features of the GMPEs considered in this study.

651 (*) the generic model is used, no stress-parameter scaling.

652 (++) no regional correction is applied. $Z_{2.5}=0.28 \mathrm{~km}$ for $V s 30=1500 \mathrm{~m} / \mathrm{s}$ and $Z_{2.5}=0.57 \mathrm{~km}$ for $V s 30=800 \mathrm{~m} / \mathrm{s}$ 653 (based on empirical relations for California, see Campbell \& Bozorgnia, 2014).

654 (**)no regional correction is applied. $Z_{1.0}=0.03 \mathrm{~km}$ for $V s 30=800 \mathrm{~m} / \mathrm{s}$ (based on empirical relations for

\begin{tabular}{|c|c|c|c|c|c|c|c|}
\hline & & $\begin{array}{c}\text { Akkar et al. } \\
(2014)\end{array}$ & $\begin{array}{l}\text { Ameri } \\
(2014)\end{array}$ & $\begin{array}{c}\text { Bindi et } \\
\text { al. (2014) }\end{array}$ & $\begin{array}{l}\text { Boore et } \\
\text { al. (2014) }\end{array}$ & $\begin{array}{l}\text { Cauzzi et } \\
\text { al. (2015) }\end{array}$ & $\begin{array}{c}\text { Campbell } \\
\& \\
\text { Bozorgnia } \\
(2014) \\
\end{array}$ \\
\hline Mw & $R[\mathrm{~km}]$ & \multicolumn{6}{|c|}{$\kappa_{0, \text { IRVT }}[\mathbf{s}]$} \\
\hline 5 & 5 & 0.031 & 0.025 & 0.027 & 0.029 & 0.024 & 0.020 \\
\hline 5 & 10 & 0.029 & 0.027 & 0.031 & 0.030 & 0.024 & 0.023 \\
\hline 5 & 20 & 0.028 & 0.029 & 0.033 & 0.031 & 0.025 & 0.025 \\
\hline 5.5 & 5 & 0.031 & 0.028 & 0.029 & 0.028 & 0.024 & 0.023 \\
\hline 5.5 & 10 & 0.03 & 0.030 & 0.032 & 0.029 & 0.024 & 0.026 \\
\hline 5.5 & 20 & 0.029 & 0.032 & 0.035 & 0.029 & 0.024 & 0.028 \\
\hline 6 & 5 & 0.032 & 0.030 & 0.030 & 0.037 & 0.023 & 0.023 \\
\hline 6 & 10 & 0.031 & 0.032 & 0.033 & 0.038 & 0.023 & 0.025 \\
\hline 6 & 20 & 0.03 & 0.033 & 0.035 & 0.038 & 0.024 & 0.027 \\
\hline 6.5 & 5 & 0.032 & 0.030 & 0.030 & 0.036 & 0.024 & 0.023 \\
\hline 6.5 & 10 & 0.031 & 0.032 & 0.032 & 0.037 & 0.024 & 0.025 \\
\hline 6.5 & 20 & 0.031 & 0.032 & 0.034 & 0.037 & 0.024 & 0.026 \\
\hline \multicolumn{2}{|c|}{ mean= } & 0.030 & 0.030 & 0.032 & 0.033 & 0.024 & 0.024 \\
\hline \multicolumn{2}{|c|}{ standard deviation= } & 0.0012 & 0.0023 & 0.0025 & 0.0041 & 0.00045 & 0.0022 \\
\hline
\end{tabular}

Table 2. Host Ko,IRVt values estimated for each GMPE for several magnitude-distance scenarios and for $V s 30=800 \mathrm{~m} / \mathrm{s}$. See text for more details. 

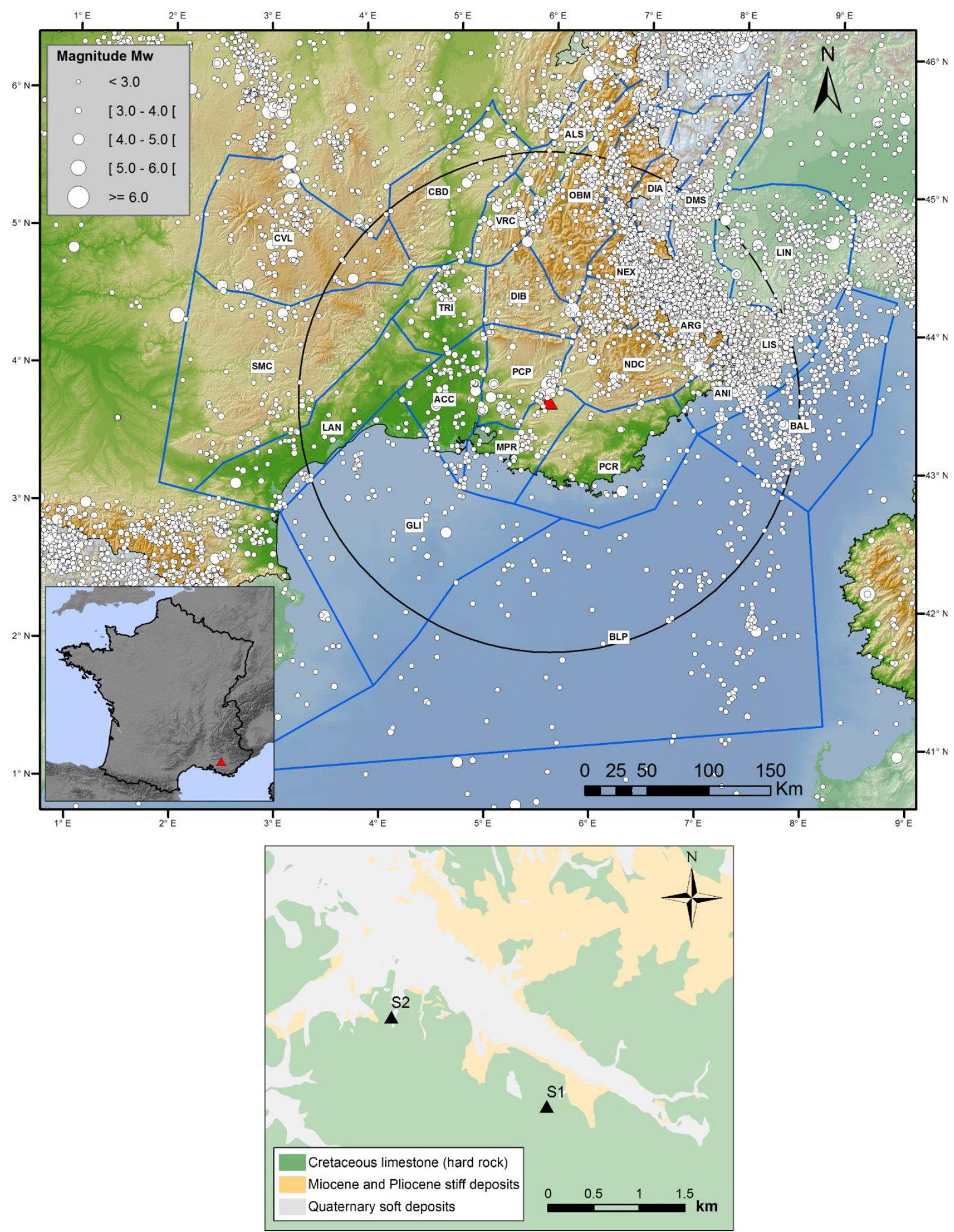

Figure 1. Upper panel: Location of the target site (red triangle). The seismicity catalogue (from 463 to 2012) compiled for the PSHA study is shown. Blue polygons represent the area source model (SM1) used as the reference model in the PSHA calculations for the sensitivity analysis. Black circle marks the $200 \mathrm{~km}$ radius around the site. Lower panel: simplified geological map of the target area. Stations S1 and S2 are located on outcropping limestone. The control point for the PSHA calculations is co-located with S2 station. 

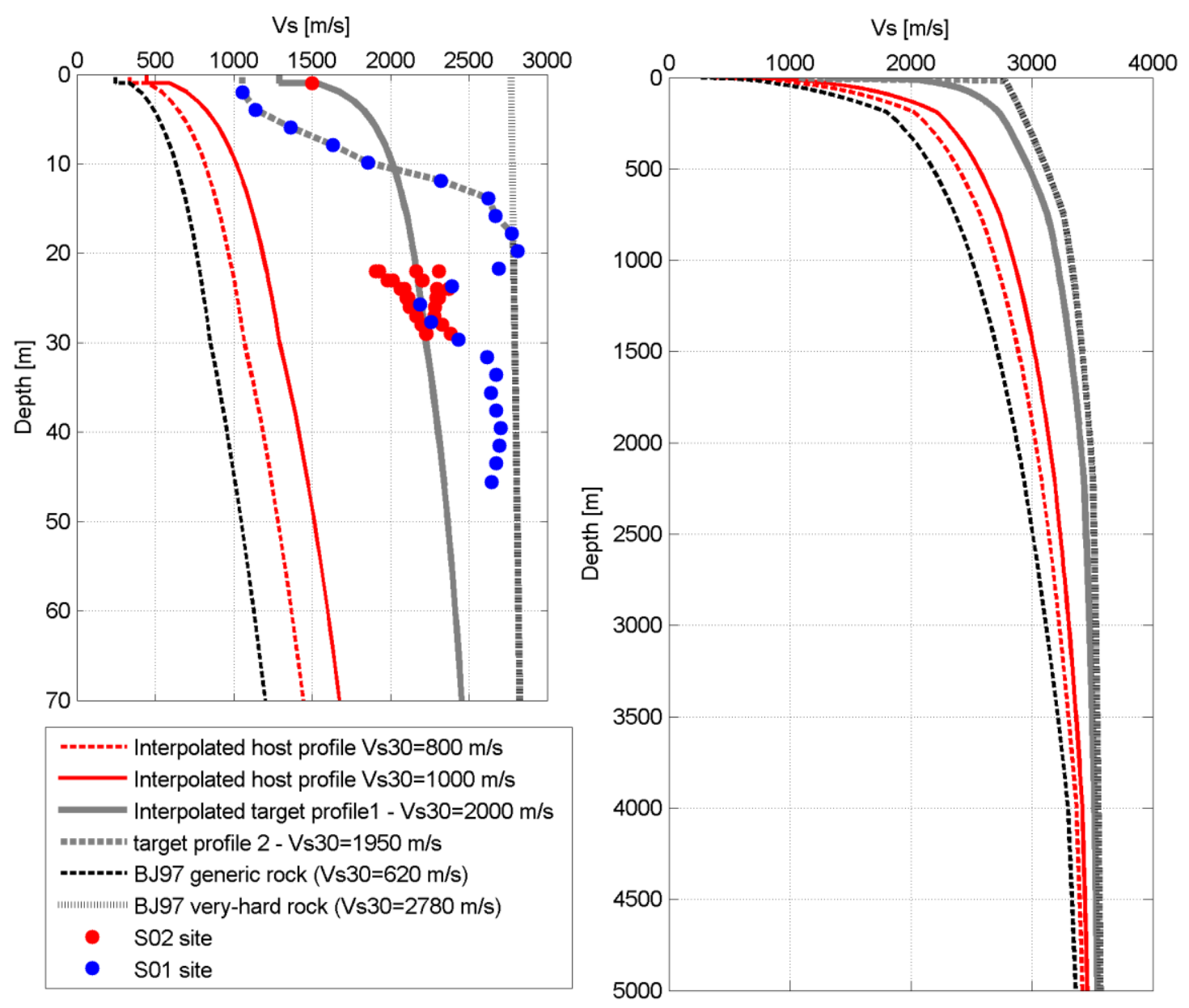

Figure 2: Vs measurements on the studied site at S01 (blue dots) and S02 (red dots) stations (about $2 \mathrm{~km}$ apart) located on the in limestone outcropping areas. The Boore and Joyner (1997) generic Vs profiles and the host and target Vs profiles defined in this study for different Vs30 values are shown between $0-70 \mathrm{~m}$ depth (left) and between $0-5 \mathrm{~km}$ depth (right). 


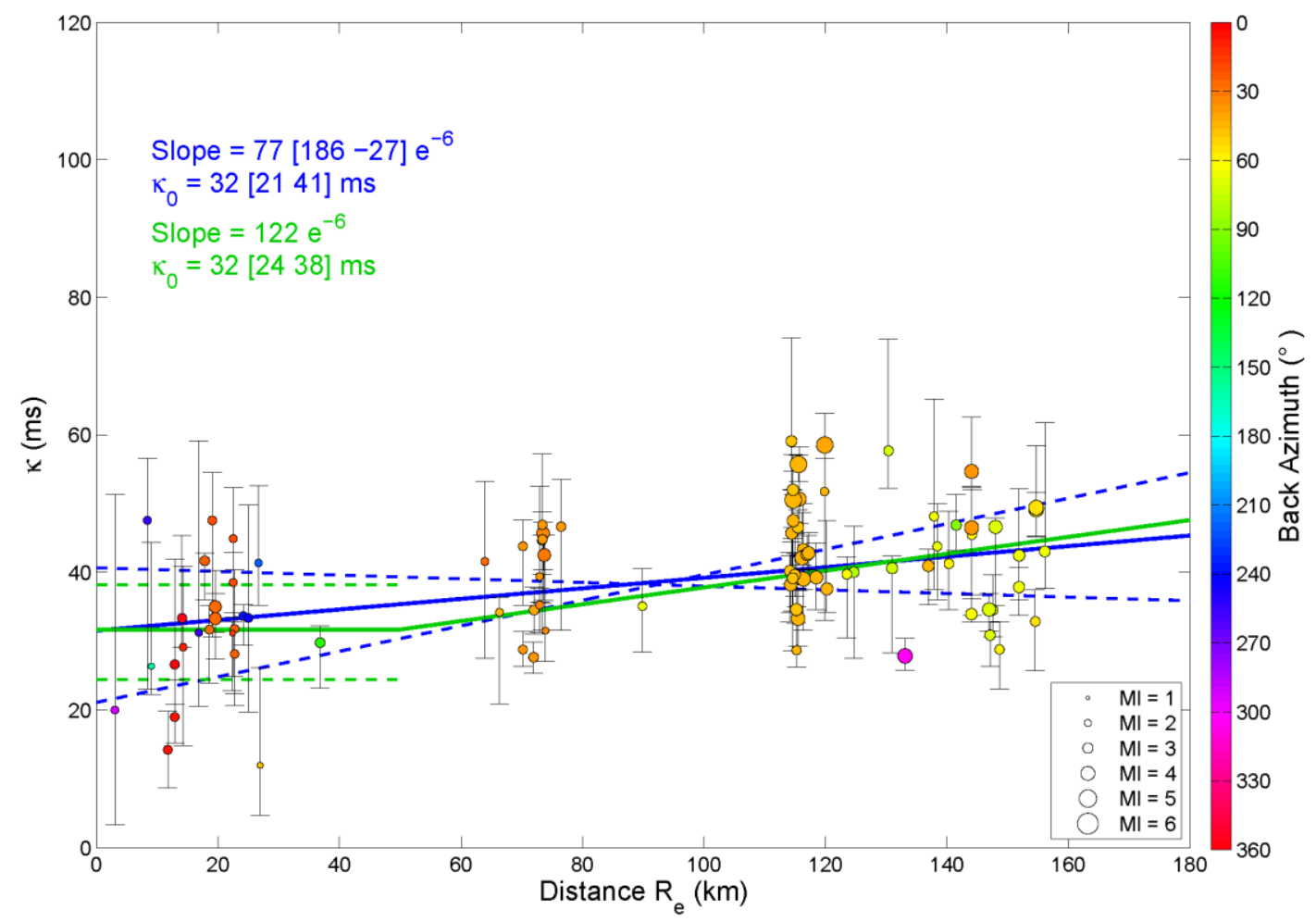

677 Figure $3: \kappa$ and $\kappa_{0}$ estimations (in milliseconds) for the studied site. Earthquake records at both S01 and S02 stations are exploited. The size of points is proportional to the earthquake magnitude. The color of points is related to earthquake back-azimuth. Mean $\kappa_{0}$ and associated standard deviation obtained using earthquakes with epicentral distances lower that $50 \mathrm{~km}$ are shown in green. Mean $\kappa_{0}$ and associated standard deviation obtained based on the computation of linear regressions on the whole epicentral distance range, minimizing and maximizing the possible $\kappa_{R}$ slope, are shown in blue. 

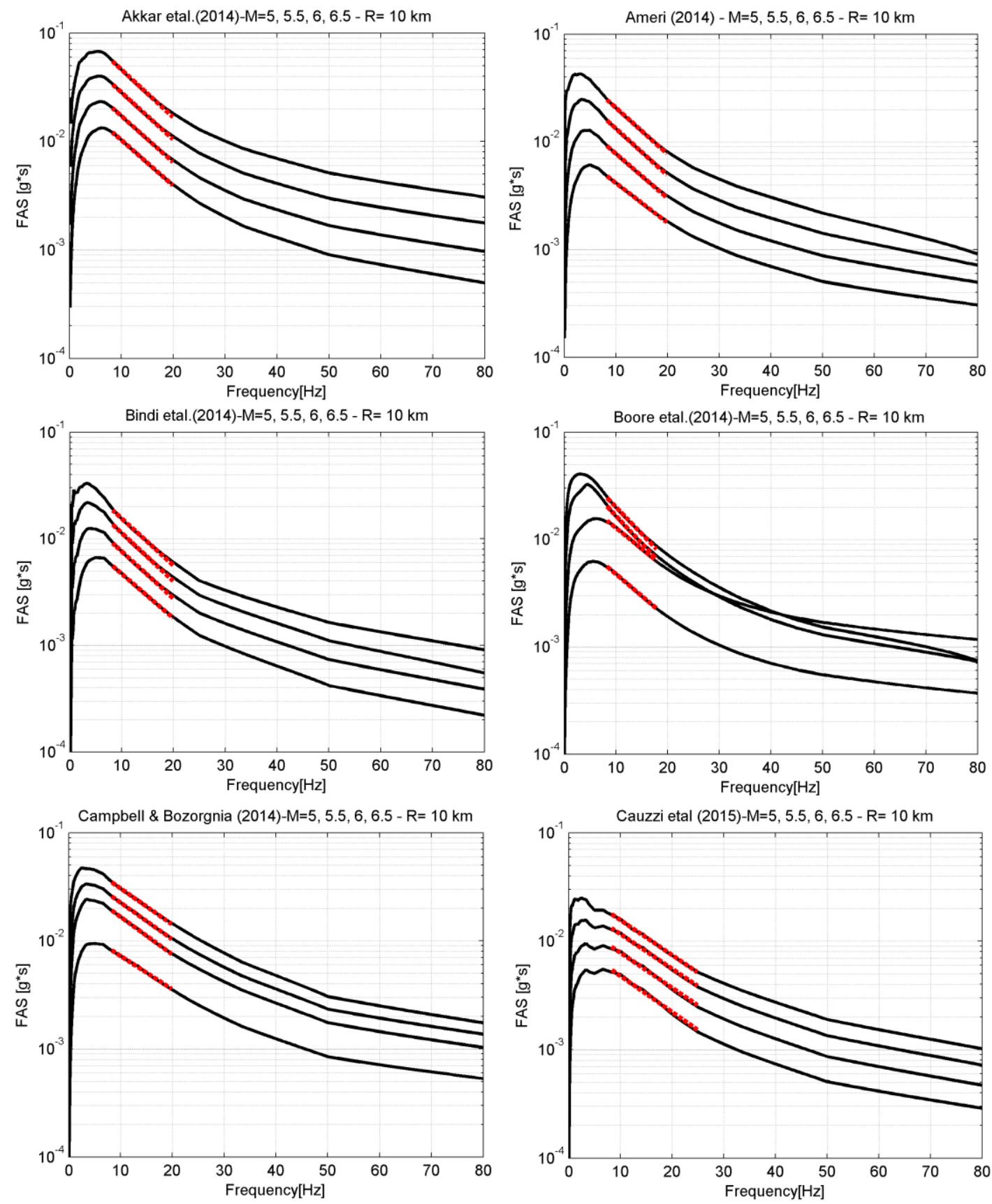

Figure 4 : Estimation of host $\kappa_{0, \mathrm{IRV}}$ for the selected GMPEs. The IRVT-derived Fourier Amplitude Spectra, FAS are presented for $M w=5.0,5.5,6.0$ and 6.5 at $10 \mathrm{~km}$ distance for $\mathrm{Vs} 30=800 \mathrm{~m} / \mathrm{s}$ and strikeslip mechanism. The fit of the kappa model to each FAS is shown by the red lines and $\kappa_{0, \text { IRvT }}$ are reported in Table 2. 

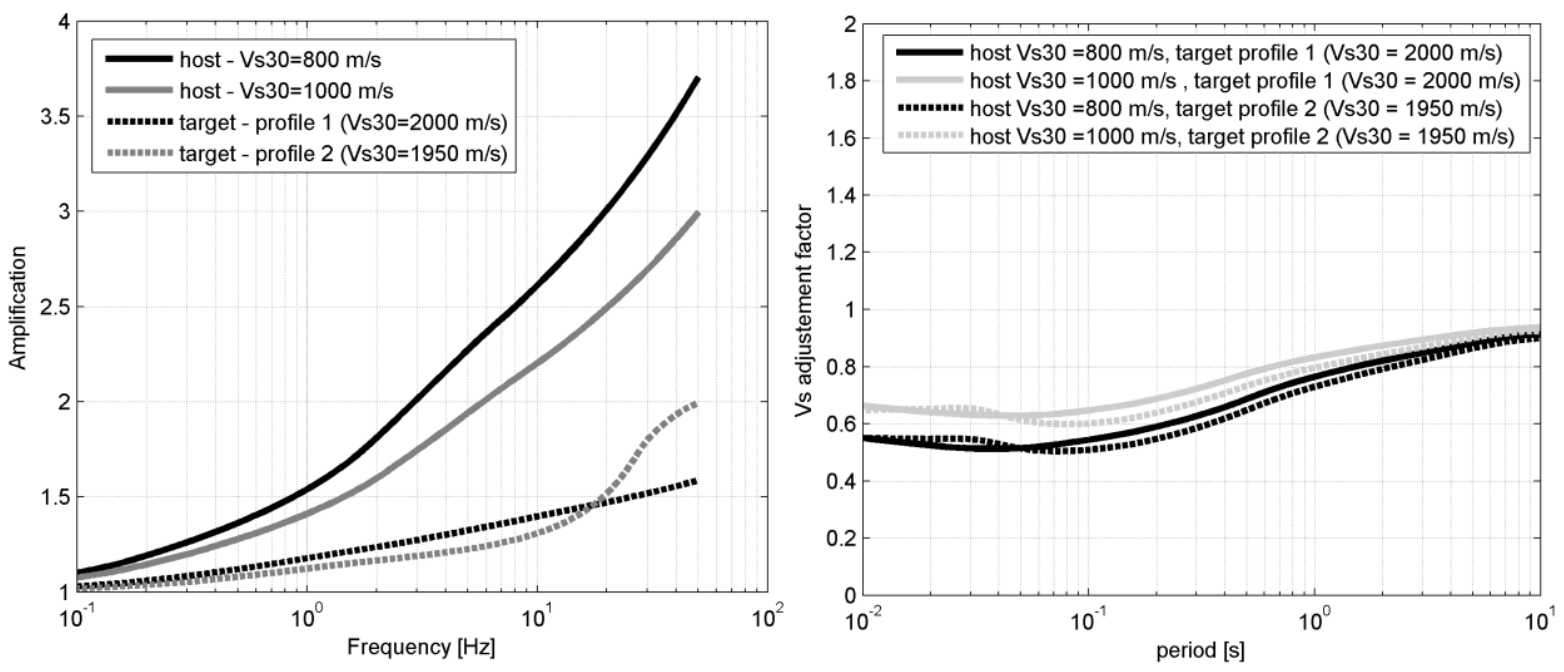

Figure 5 : Left: Square-root-impedance method amplifications for the host and target Vs profiles presented in Figure 2. Right: Vs host-to-target adjustment factors in terms of response spectra for host $V_{s 30}$ of $800 \mathrm{~m} / \mathrm{s}$ and $1000 \mathrm{~m} / \mathrm{s}$ and a target profile $1\left(V_{s} s_{0}=2000 \mathrm{~m} / \mathrm{s}\right)$ and profile $2\left(V_{330}=1950 \mathrm{~m} / \mathrm{s}\right)$.

Akkar et al.(2014), M=5.5, $R=10 \mathrm{~km}$

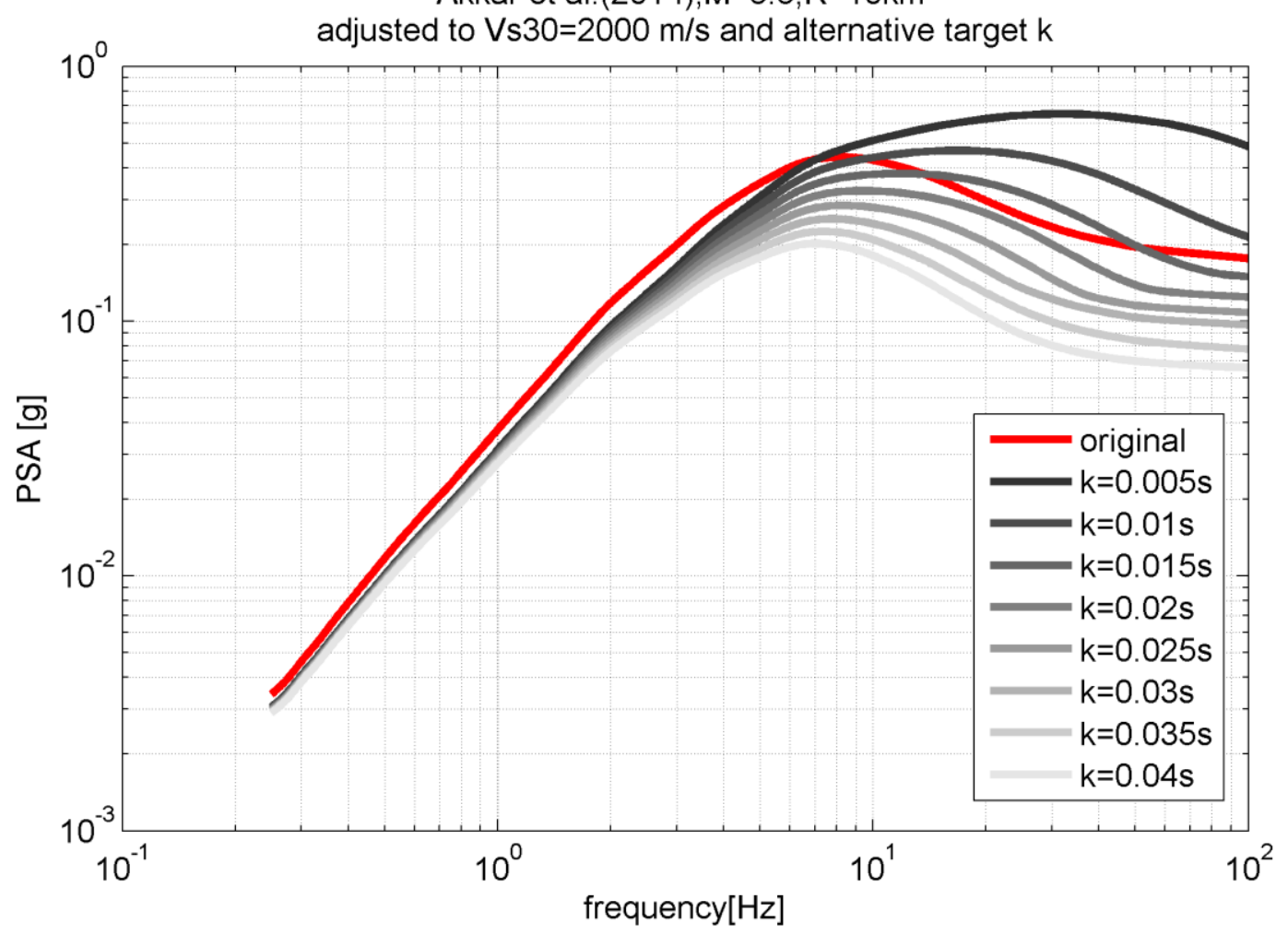

Figure 6 : Example of Vs- $\kappa$ adjustment of the Akkar et al. (2014) GMPE (for M=5.5 at $10 \mathrm{~km}$ ) considering 

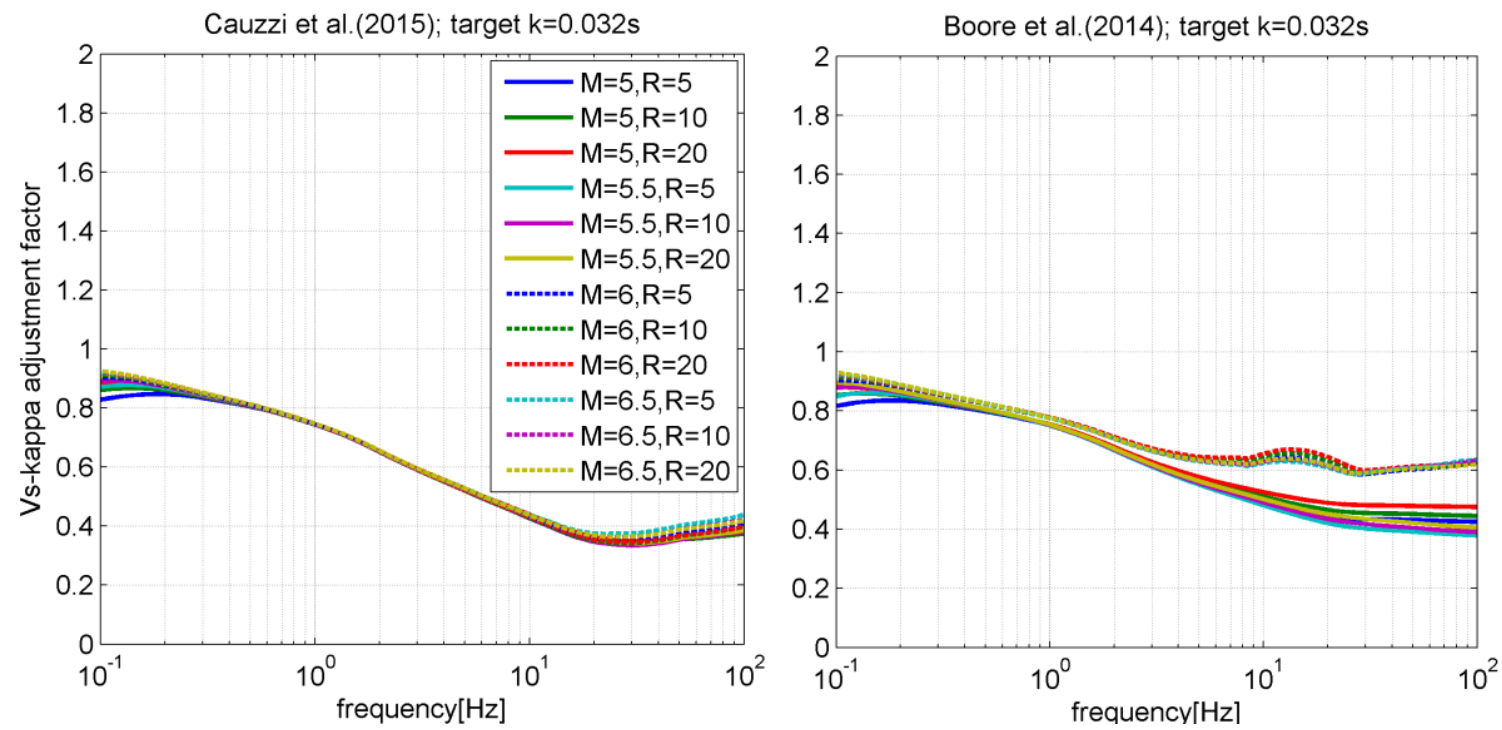

Figure 7 : Example of Vs- $\kappa$ adjustement factors for target $V s 30=2000 \mathrm{~m} / \mathrm{s}$ and target $\kappa_{0}=0.032 \mathrm{~s}$
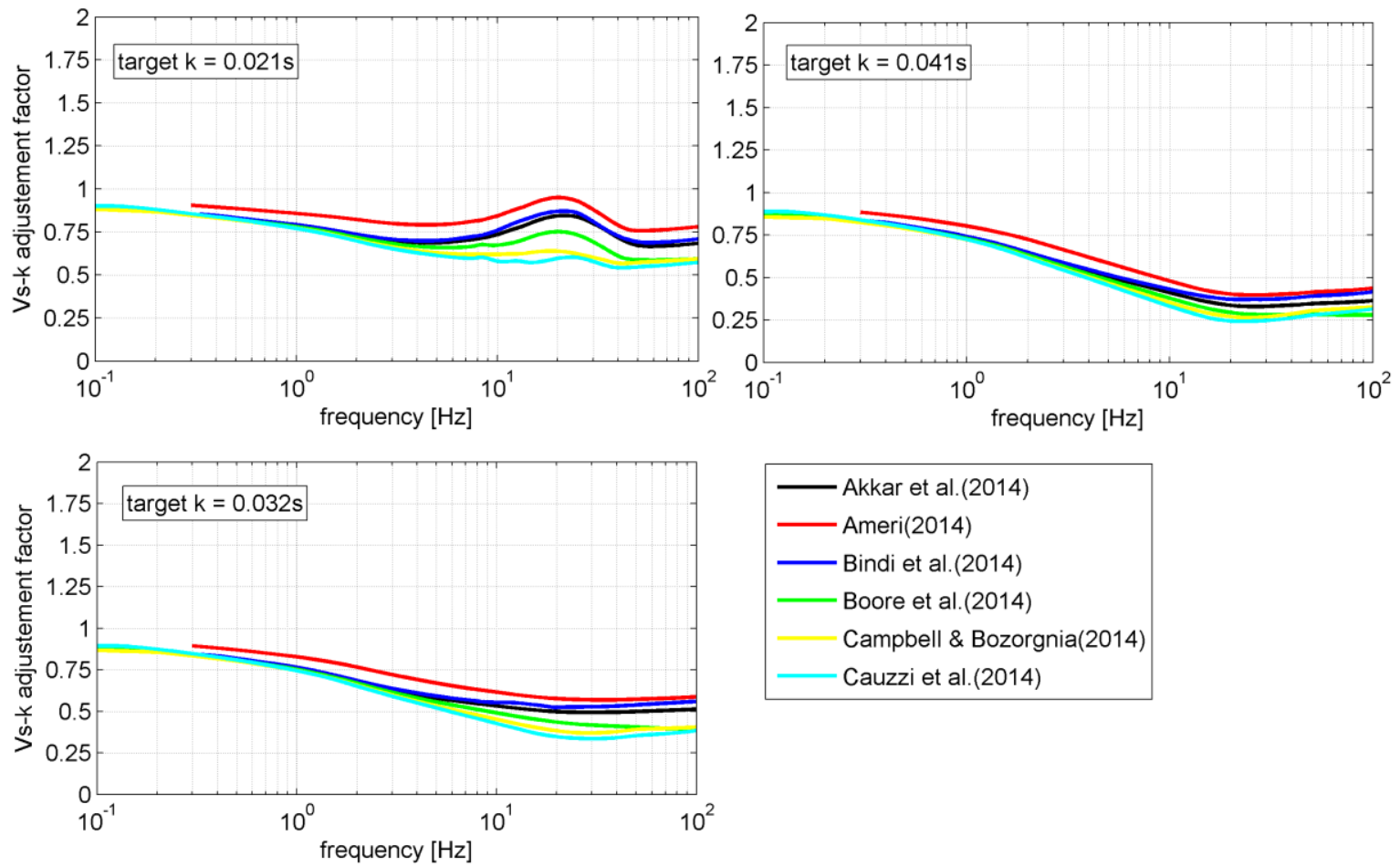

Figure 8 : host-to-target Vs- $\kappa$ adjustment factors for the selected GMPEs (for Mw=5.5 at $10 \mathrm{~km}$ ) considering a target $\mathrm{Vs} 30=2000 \mathrm{~m} / \mathrm{s}$ and target $\kappa_{0}=0.032 \mathrm{~s}$ (top), $\kappa_{0}=0.021 \mathrm{~s}$ (middle) and $\kappa_{0}=0.041 \mathrm{~s}$ (bottom). 


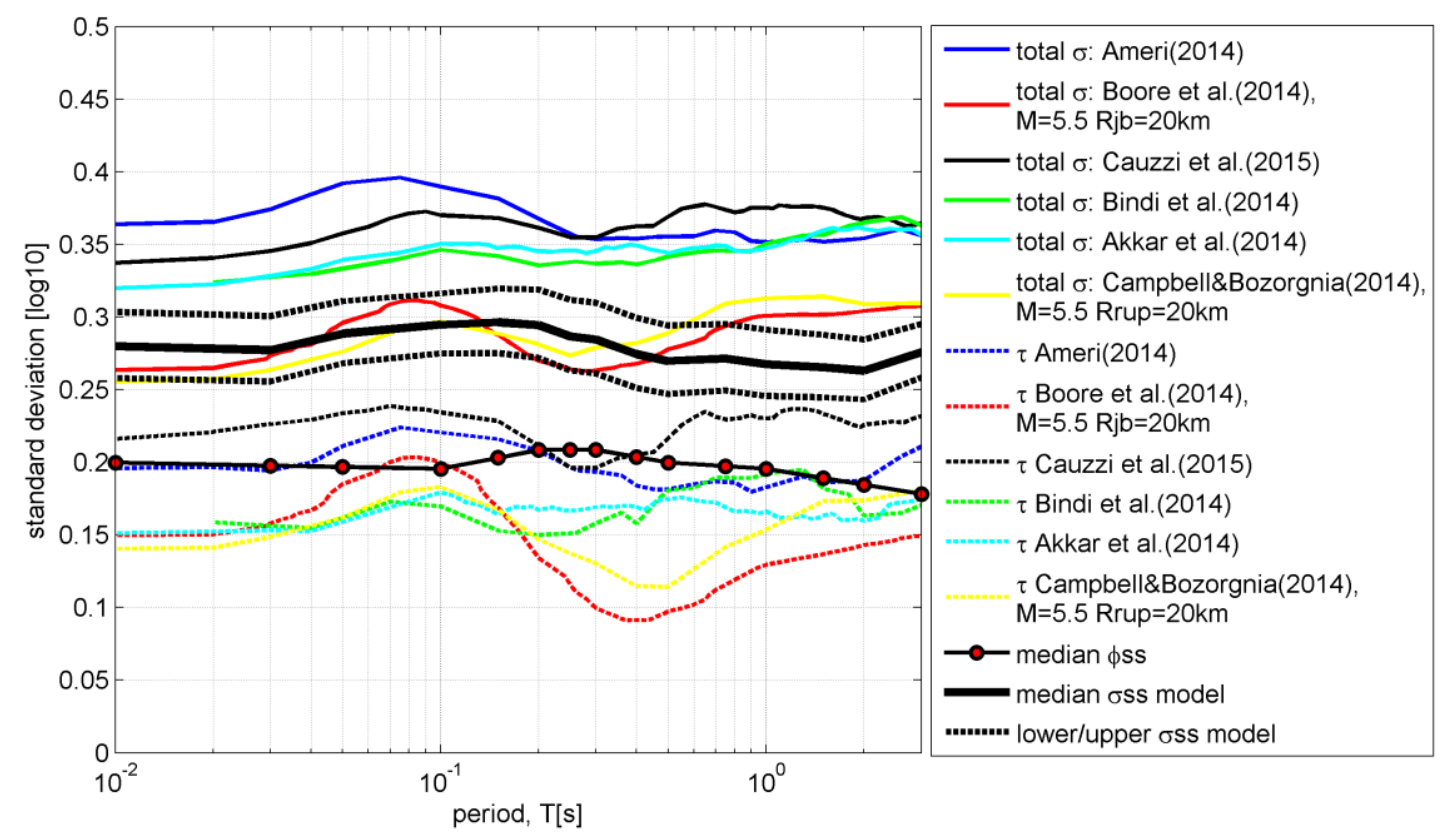

Figure 9 : Sigma [ $\left.\log _{10}\right]$ models as a function of spectral period for the GMPEs considered in this study. The between-event standard deviations $(\tau)$ are reported as dashed lines. The median, upper and lower $\left(_{\text {ss }}\right)$ models are shown by the thick black line. The median $\phi_{\text {ss }}$ model is the constant model proposed by 715 Rodriguez-Marek et al. (2013). 

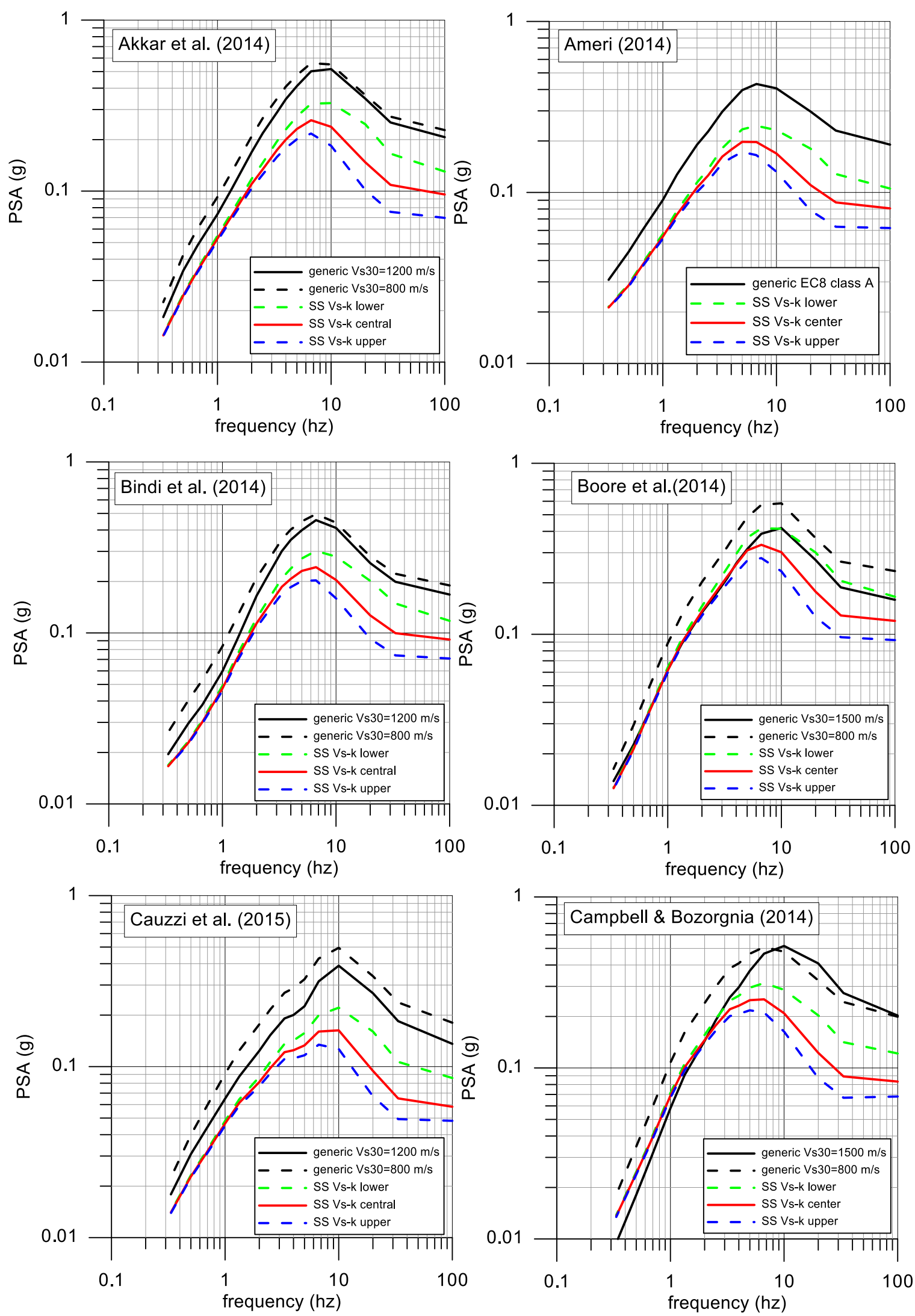

Figure 10 : Uniform Hazard Spectra (UHS) at 10000-year return period obtained for the considered GMPEs. For each GMPEs, the site-specific (SS) UHS obtained by the partially nonergodic PSHA are compared to the generic UHS obtained without GMPEs adjustment considering a Vs30 $=800 \mathrm{~m} / \mathrm{s}$ (dashed black lines) and a Vs30 corresponding to the upper limit of the validity domain of each GMPE (thick black lines). 


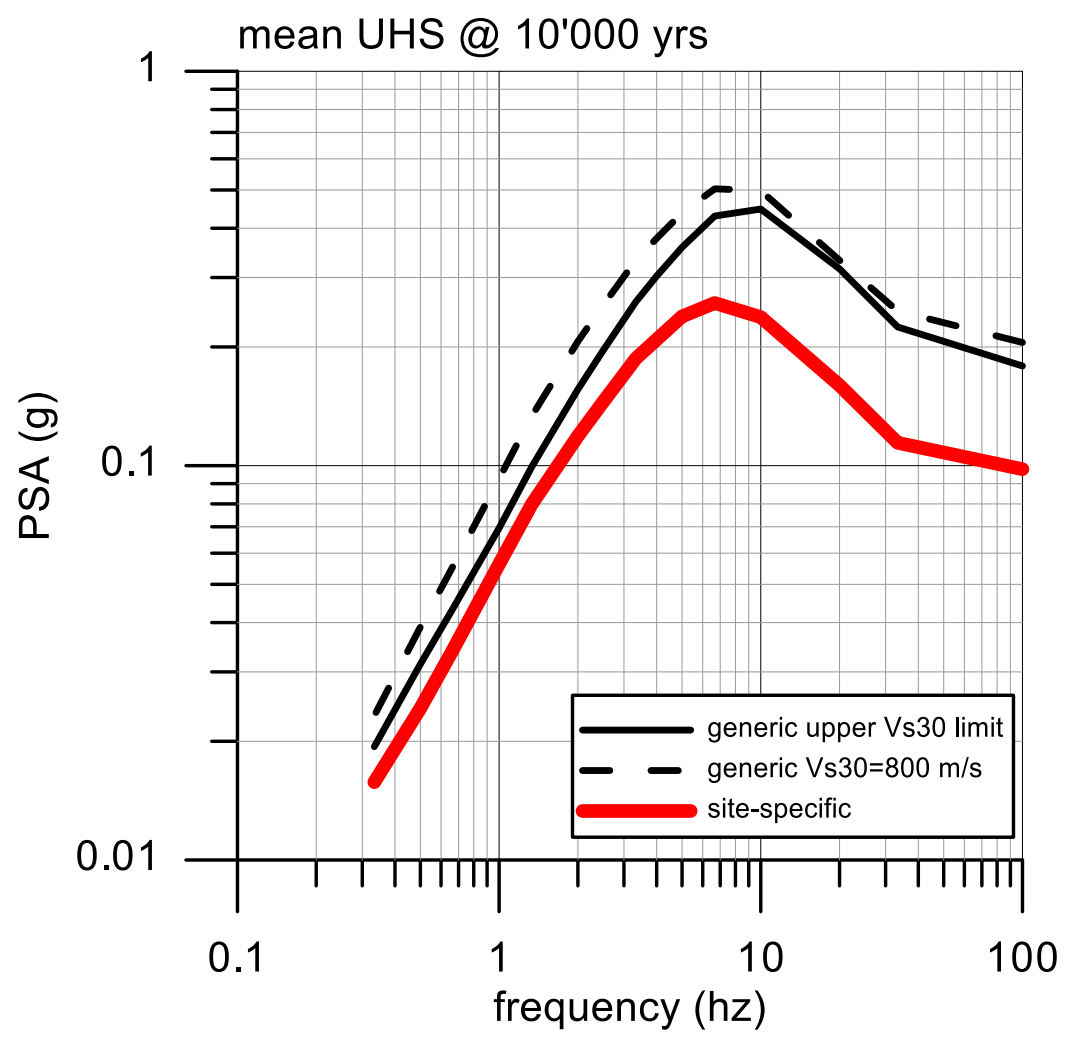

Figure 11 : Site-specific partially non- ergodic mean Uniform Hazard Spectra (UHS) at 10000-year return period for the reduced SSC logic tree considering equal weights for GMPEs and target $\kappa_{0}$ values. Also shown are the mean UHS obtained from generic (ergodic) PSHA considering Vs30=800 $\mathrm{m} / \mathrm{s}$ and Vs30 equal to the upper limit of the validity domain for each GMPE. 